NASA/TM-2001-210761

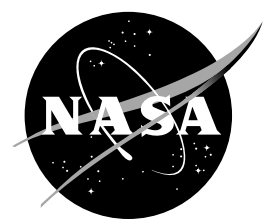

\title{
Towards Accurate Prediction of Turbulent, Three-Dimensional, Recirculating Flows With the NCC
}

A. Iannetti and R. Tacina

Glenn Research Center, Cleveland, Ohio

S.-M. Jeng and J. Cai

University of Cincinnati, Cincinnati, Ohio 
Since its founding, NASA has been dedicated to the advancement of aeronautics and space science. The NASA Scientific and Technical Information (STI) Program Office plays a key part in helping NASA maintain this important role.

The NASA STI Program Office is operated by Langley Research Center, the Lead Center for NASA's scientific and technical information. The NASA STI Program Office provides access to the NASA STI Database, the largest collection of aeronautical and space science STI in the world. The Program Office is also NASA's institutional mechanism for disseminating the results of its research and development activities. These results are published by NASA in the NASA STI Report Series, which includes the following report types:

- TECHNICAL PUBLICATION. Reports of completed research or a major significant phase of research that present the results of NASA programs and include extensive data or theoretical analysis. Includes compilations of significant scientific and technical data and information deemed to be of continuing reference value. NASA's counterpart of peerreviewed formal professional papers but has less stringent limitations on manuscript length and extent of graphic presentations.

- TECHNICAL MEMORANDUM. Scientific and technical findings that are preliminary or of specialized interest, e.g., quick release reports, working papers, and bibliographies that contain minimal annotation. Does not contain extensive analysis.

- CONTRACTOR REPORT. Scientific and technical findings by NASA-sponsored contractors and grantees.
- CONFERENCE PUBLICATION. Collected papers from scientific and technical conferences, symposia, seminars, or other meetings sponsored or cosponsored by NASA.

- SPECIAL PUBLICATION. Scientific, technical, or historical information from NASA programs, projects, and missions, often concerned with subjects having substantial public interest.

- TECHNICAL TRANSLATION. Englishlanguage translations of foreign scientific and technical material pertinent to NASA's mission.

Specialized services that complement the STI Program Office's diverse offerings include creating custom thesauri, building customized data bases, organizing and publishing research results ... even providing videos.

For more information about the NASA STI Program Office, see the following:

- Access the NASA STI Program Home Page at http://www.sti.nasa.gov

- E-mail your question via the Internet to help@sti.nasa.gov

- Fax your question to the NASA Access Help Desk at 301-621-0134

- Telephone the NASA Access Help Desk at 301-621-0390

- Write to:

NASA Access Help Desk

NASA Center for AeroSpace Information 7121 Standard Drive

Hanover, MD 21076 
NASA/TM-2001-210761

AIAA-2001-0809

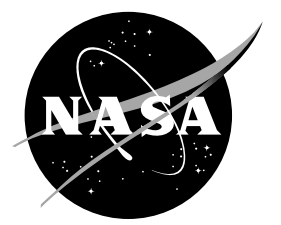

\title{
Towards Accurate Prediction of Turbulent, Three-Dimensional, Recirculating Flows With the NCC
}

\author{
A. Iannetti and R. Tacina \\ Glenn Research Center, Cleveland, Ohio \\ S.-M. Jeng and J. Cai \\ University of Cincinnati, Cincinnati, Ohio
}

Prepared for the

39th Aerospace Sciences Meeting and Exhibit

sponsored by the American Institute of Aeronautics and Astronautics

Reno, Nevada, January 8-11, 2001

National Aeronautics and

Space Administration

Glenn Research Center 


\section{Acknowledgments}

We would like to thank Dot Carney and Jay Horowitz of the GVIS lab for introducing us to three-dimensional visualization. This work was supported by the High Performance Computing and Communication Program, the Smart Engine Components Program, and the Ultra Efficient Engine Technology program.

This report contains preliminary

findings, subject to revision as

analysis proceeds.

Available from

NASA Center for Aerospace Information 7121 Standard Drive

Hanover, MD 21076

Price Code: A03
National Technical Information Service 5285 Port Royal Road Springfield, VA 22100 Price Code: A03 


\title{
Towards Accurate Prediction of Turbulent, Three- Dimensional, Recirculating Flows with the NCC
}

\author{
A. Iannetti and R. Tacina \\ National Aeronautics and Space Administration \\ Glenn Research Center \\ Cleveland, Ohio 44135 \\ S.-M. Jeng ${ }^{*}$ and J. Cai \\ University of Cincinnati \\ Cincinnati, Ohio 45221-0001
}

\begin{abstract}
$\underline{\text { ABSTRACT }}$
The National Combustion Code (NCC) was used to calculate the steady state, non-reacting flow field of a prototype Lean Direct Injection (LDI) swirler. This configuration used nine groups of eight holes drilled at a thirty-five degree angle to induce swirl. These nine groups created swirl in the same direction, or a co rotating pattern. The static pressure drop across the holes was fixed at approximately four percent. Computations were performed on one quarter of the geometry, because the geometry is considered rotationally periodic every ninety degrees. The final computational grid used was approximately 2.26 million tetrahedral cells, and a cubic non-linear $\mathrm{k}-$ epsilon model was used to model turbulence. The NCC results were then compared to time averaged Laser Doppler Velocimetry (LDV) data. The LDV measurements were performed on the full geometry, but four ninths of the geometry was measured. One, two, and three-dimensional representations of both flow fields are presented. The NCC computations compare both qualitatively and quantitatively well to the LDV data, but differences exist downstream. The comparison is encouraging, and shows that NCC can be used for future injector design studies. To improve the flow prediction accuracy of turbulent, three-dimensional, recirculating flow fields with the NCC, recommendations are given.
\end{abstract}

\section{INTRODUCTION}

Most combustion processes have, in some way or another, a recirculating flow field. This recirculation stabilizes the reaction zone, or flame, but an unnecessarily large recirculation zone can result in high NOx values for combustion systems. The size of this

\footnotetext{
* NASA Resident Research Associate at Glenn Research Center.
}

recirculation zone is crucial to the performance of state of the art, low emissions hardware. If this is a largescale combustion process, the flow field will probably be turbulent, and therefore three-dimensional. This paper will deal primarily with flow fields resulting from Lean Direct Injection (LDI) concepts. LDI is a concept that depends heavily on the design of the swirler. The LDI concept has the potential to reduce NOx values from $50-70 \%$ of current values, with good flame stability characteristics. It is cost effective and (hopefully) beneficial to do most of the design work for an LDI swirler using Computer Aided Design (CAD) and Computer Aided Engineering (CAE) tools. Computational Fluid Dynamics (CFD) codes are a CAE tool that can calculate three-dimensional flows in complex geometries. However, CFD codes are only beginning to correctly calculate the flow fields for complex devices, and the related combustion models usually remove a large portion of the flow physics.

The National Combustion Code (NCC) is a state of the art CFD program specifically designed for combustion processes. A short summary of the features of NCC pertaining to this paper are: the use of unstructured grids, ${ }^{1}$ massively parallel computing with almost perfectly linear scalability, ${ }^{2}$ a dynamic wall function with the effect of adverse pressure gradient, ${ }^{3}$ low Reynolds number wall treatment, ${ }^{4}$ and a cubic nonlinear k-epsilon turbulence model. ${ }^{5,6}$ The combination of these features is usually not available in other CFD codes and gives the NCC an advantage when computing recirculating turbulent flows. These features need to be validated, before the NCC is accepted as a design tool. The NCC has previously undergone benchmarking for simple flows, ${ }^{7}$ and large-scale validations are being conducted. ${ }^{8}$

The purpose of this study is to quantify how well the NCC calculates a turbulent, three-dimensional, recirculating flow field. The comparison is against three-dimensional Laser Doppler Velocimetry (LDV) measurements on a prototype LDI swirler. This 
comparison should show that the NCC could be a useful design tool for LDI injectors.

\section{THE LDI BENCMARK CASE}

\section{$\underline{\text { Geometry and Computational Grid }}$}

The LDI swirler is comprised of holes drilled at a 35 degree angle to induce swirl. There are nine sets of eight holes rotating in the same direction, or co rotating. Figure 1 and Figure 2 show the LDI swirler solid geometry at various angles. The swirler was placed in a $76.2 \mathrm{~mm}$ square pipe. (As indicated by a square box placed around the swirler.) The solid geometry model was created using Pro Engineer. The computational grid was generated using the CFDGEOM program. ${ }^{9}$ A tetrahedral grid was used throughout the computational domain. Hybrid prismatic/tetrahedral grids were attempted, but the quality of the prism cells was unacceptable. Looking at Figure 1 and Figure 2, it is obvious (to the author) that the geometry is rotationally periodic every ninety degrees. A special modification was made to the model because of the periodic boundary conditions. A small "sting" was added to the centerline of the Pro Engineer model. This "sting" was added to prevent both periodic boundary conditions from touching one cell. This condition is not desirable, because it causes numerical instabilities. (This is because the NCC periodic boundary conditions can have a different number of cells on each side.) To create this section, the Pro Engineer model was modified using the "cut" operation. The Pro Engineer model was then translated into IGES format, for use as Non Uniform Rational B Splines (NURBS) surfaces in CFD-GEOM. This method was very time efficient. It took only 20 minutes to generate the largest meshes using this grid generation "system". During the start of this study, computational grids with 60,000 cells were used. The grid was refined until acceptable results were obtained. The final computational grid used was approximately 2.26 million cells. Figure 3 and Figure 4 show the computational grid for the entire domain and at the swirler.

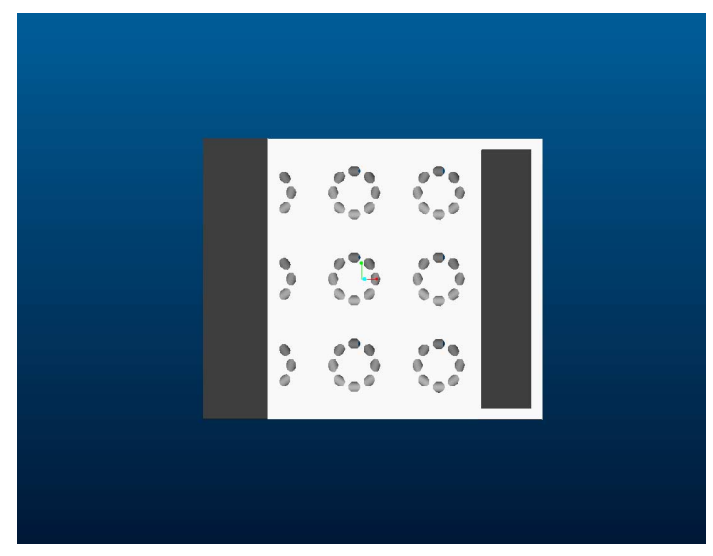

Figure 1 - Rear View of the LDI 35 Degree Co Rotating Swirler

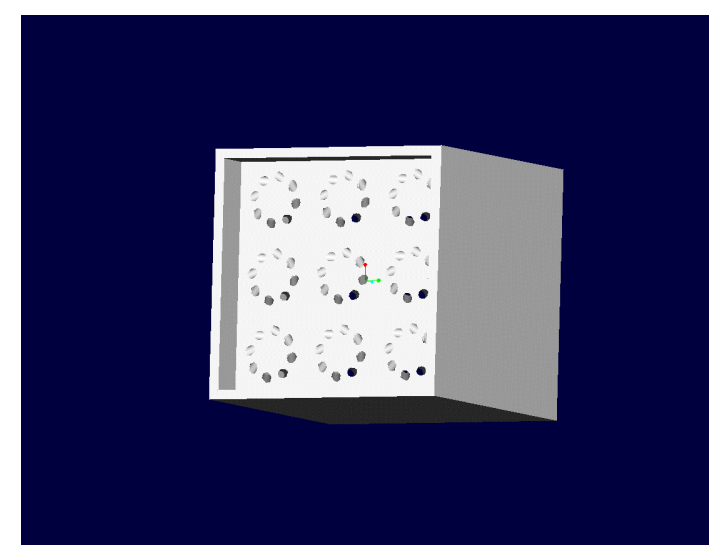

Figure 2 - Front View of the LDI 35 Degree Co Rotating Swirler

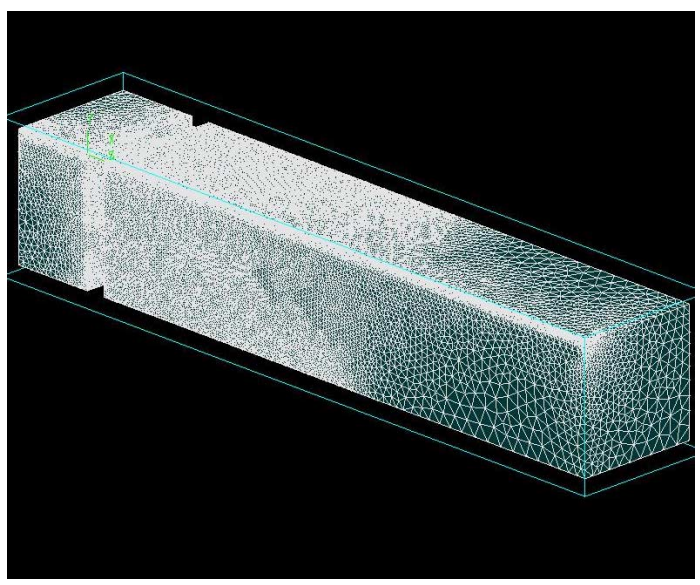

Figure 3 - Overview of the Final NCC Computational Grid at $\mathbf{2 . 2 6}$ million cells 


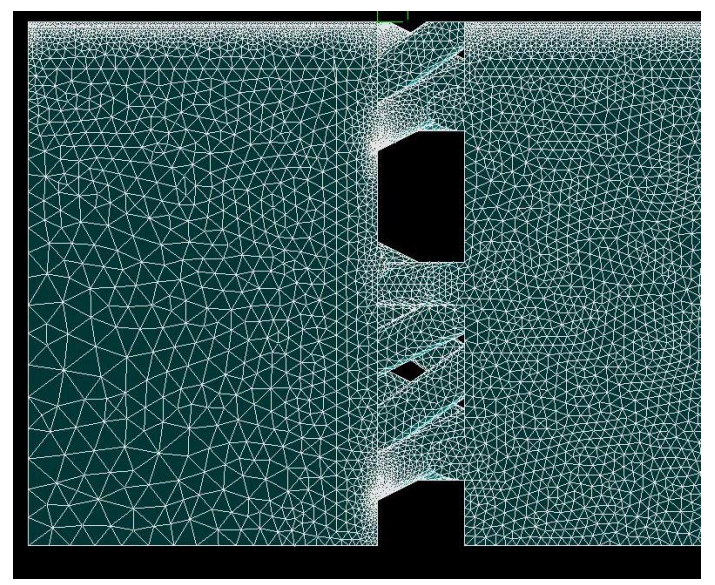

Figure 4 - Close up of the final NCC Computational Grid at the Swirler Region

\section{Flow Conditions}

The LDI 35 degree co rotating swirler geometry was only computed as a non-reacting flow case. The NCC computations and LDV measurements were performed at approximately atmospheric pressure, with a $4 \%$ static pressure drop across the swirler. Figure 5 shows an overview of the flow conditions for both the NCC computations and LDV measurements. The turbulence intensity was assumed at $10 \%$ and the length scale was assumed 3\% the inlet diameter. The exit pressure was atmospheric, and the exit temperature was at $298 \mathrm{~K}$. The flow was confined with windowed walls for optical access.

\section{NCC Computations}

The NCC computations were run in general until the residuals were reduced three orders of magnitude. The mass flow rates at the boundary conditions were also monitored as a convergence criterion. Dissipation was set at .05 for second order dissipation $(\varepsilon 2)$ and .08 for fourth order dissipation $(\varepsilon 4) .{ }^{10}$ After the residual dropped three orders of magnitude, the $\varepsilon 2$ was set to zero, and the $\varepsilon 4$ was set to 0.03125 . The value of $k 2$, the constant that scales the second order dissipation pressure switch, was set at 0.25. Setting the second order dissipation to zero greatly improves the numerical accuracy, but if this initialization procedure was not done, the NCC sometimes ran into stability problems. A CFL number of 2.0 was used.

The cubic non-linear k-epsilon model was used. This model was chosen because of its superior performance for computing swirling flows, while being computationally efficient compared to Reynolds stress

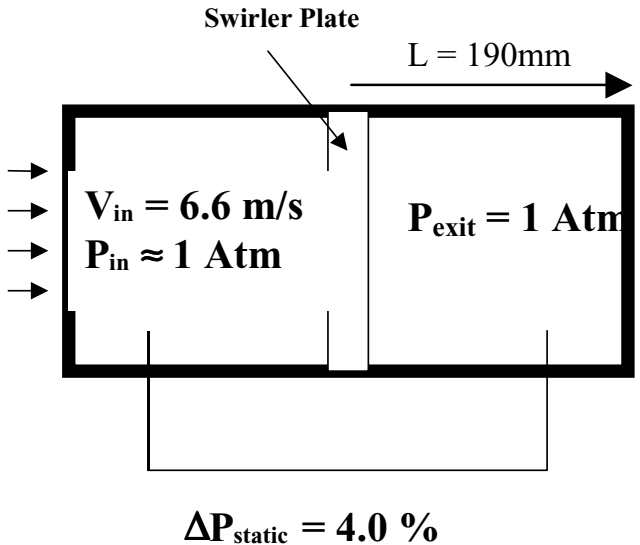

\section{Figure 5 - Overview of Boundary Conditions for the LDI 35 Degree Co Rotating Swirler}

turbulence models. No other turbulence models were used or compared. Various turbulent wall conditions were used during the investigation. A "standard" wall function was originally used, but this gave extremely poor results. This wall function was then replaced in the NCC with a dynamic wall function with pressure gradient effects. This wall condition, along with the low Reynolds number variant of the cubic non-linear kepsilon model, gave very similar results. Because this wall function is so new, and not well validated, the low Reynolds number wall treatment results are reported.

Computations were originally performed on a variety of computer platforms, namely SGI Origin 2000's at NASA Ames and Linux clusters at NASA Glenn. Only Origin 2000's performed calculations on grids over one millions cells. For the largest calculations, the SGI Non Uniform Memory Architecture (NUMA) high performance computers are preferred not only because of performance, but because they are true 64 bit computers. (They can address over two GB of memory. This is needed for some pre and post processing operations.)

\section{LDV Measurements}

The LDV system used in this paper is described in detail by Jeng et al. ${ }^{11}$ Only a brief description will be given in this paper. The TSI 2D LDV measurement system $^{12}$ was used to measure the vertical velocity and one component of horizontal velocity. To get improved signals, forward scatter was used to measure the airflow field. The measurement system includes a $3 \mathrm{w}$ argon laser, an optical fiber driver, a transmitter, a signal receiver, a photomultiplier, and a signal processor. The optical transmitter and the receiver were mounted on a 3-D moveable traverse that was controlled by the 


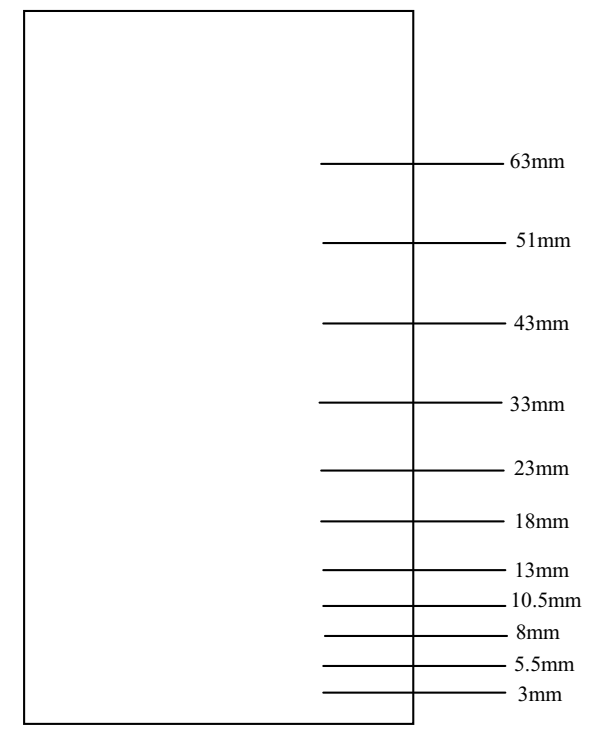

Figure 6 - LDV Measurement Locations

computer. A 500mm-focus lens transmitter and $300-\mathrm{mm}$ focus lens receiver were used in the measurement. The measurement involved the mean velocity and turbulent characteristics. Though the refraction of the laser beams through the walls may lead to the separation of the two focus points, the thin walls will decrease this separation. By using the coincidence selection on the software, the shear stress was obtained. Usually, the data rate of the measurements was 600/s and 3000 measurements were collected at each data position. The time range is about 5 seconds per point.

In the experiment, a TSI six jet aerosol was used to generate seeding particles, which have a diameter of $3 \mu \mathrm{m}$. It almost has no slip relative to the air and has good refracting characteristic. Measurements were obtained at twelve axial locations downstream of the multi-swirler array. Locations of the measurements are shown in Figure 6. At each location, due to the similarity of the design, only $4 / 9$ of the area was measured. The measurement resolution is $1 \times 1 \mathrm{~mm}$ for the first five locations and $2 \times 2 \mathrm{~mm}$ resolution for the other locations.

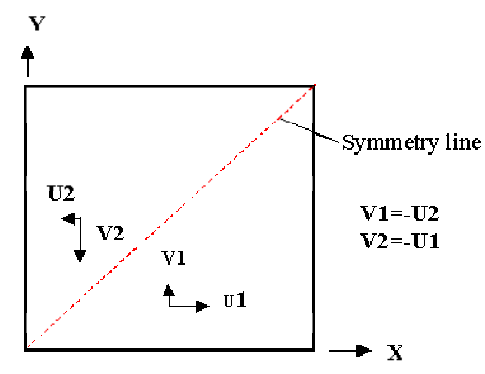

Figure 7 - Anti-Symmetry of the Horizontal Velocity Used in the LDV Measurements
In order to represent the entire flow field, the other component of the horizontal velocity, U, was obtained by a so called "symmetry method". The method can be explained by Figure 7. In Figure 7, we assume that the horizontal velocity is anti-symmetry relative to the diagonal line of the area. So we have $\mathrm{u} 1=-\mathrm{v} 2$ and $\mathrm{v} 1=-\mathrm{u} 2$. By this method, we obtained the information of the other component. Though it is not accurate, it gave us enough information to understand the horizontal velocity distribution of the flow field. The estimated error for the time averaged and RMS velocities is $0.25 \mathrm{~m} / \mathrm{s}$.

\section{Data Reduction and Post Processing}

The NCC computations and the LDV measurements were both manipulated to give the appearance of the full geometry. The NCC calculations were periodically mirrored every ninety degrees. This resulted in the post processing of over 10 million computation cells. For this purpose, a four processor SGI Onyx 2 graphical supercomputer was used. The Ensight Gold ${ }^{13}$ post-processing package was used in parallel mode to extract results. The LDV measurements were manipulated in a similar fashion. The graphical computing requirements for the LDV measurements were far less than the NCC computations. The Tecplot ${ }^{14}$ post-processing package was used to manipulate extracted line plot data.

\section{RESULTS}

The resulting data is compared via $\mathrm{XY}$ plots, contour and vector plots, and isosurfaces. In addition, animations containing additional three-dimensional entities like elevated surfaces, stream tubes, and flow particles traces were created. These entities will not be shown because of paper size restrictions and the fact that these entities to do not display well on a twodimensional piece of paper.

Figure 8 shows isosurfaces for $\mathrm{W}$ (or the axial) velocity equal to zero. This gives a good overview of the two flows fields from both the NCC and LDV data. The isosurfaces are similar, but not the same. The NCC computations show that the recirculating regions are generally shorter that the LDV data. The corner swirlers stay centered for the NCC computations, but the LDV measurements show that the recirculation zones move toward the walls.

Figure 9 through Figure 14 show combined contour plots for velocity magnitude, as well as velocity vectors. The contours are on the same scale, but the vectors are on a similar, but not the exactly same scale. The vectors should only be used to qualitatively 
compare the NCC and the LDV data. Figure 9 shows that at the $Z=3 \mathrm{~mm}$ plane, both the NCC and LDV data produce similar results. The NCC predicts a generally stronger recirculation zone away from the jets. For Figure $10, Z=13 \mathrm{~mm}$, the NCC shows a more ordered flow field, with slightly stronger recirculation zones that are more circular. The LDV data shows a more distorted flow field, with flow from the corner swirlers starting to distort. The LDV data also indicated that the jets are still present, while the NCC data smears the jets at this location. Figure $11, \mathrm{Z}=23 \mathrm{~mm}$, shows that the NCC data still has nine strong vortices, while the LDV measurements show that most of the strong flow features have washed away. Figure $12, Z=50 \mathrm{~mm}$, gives similar results, showing that NCC still predicts features in the flow, while the LDV data shows that most of the flow features have washed away. However, these differences between the NCC and LDV data are small.

Figure 13 and Figure 14 are cuts along the $\mathrm{X}$ plane at $0 \mathrm{~mm}$ (centerline) and $19 \mathrm{~mm}$ (between the swirlers). Both the NCC and LDV data trends the same, by dissipating the jets around $30 \mathrm{~mm}$. The NCC computations predict stronger flow features that the LDV measurements. The LDV measurements are taken at 1 and $2 \mathrm{~mm}$ intervals, which could account for the stronger flow feature predicted by the NCC.

Since the prediction of recirculation zones are of primary interest, Figure 15 through Figure 20 show contours of the axial (W) velocity. At $\mathrm{Z}=3 \mathrm{~mm}$, Figure 15 shows that the NCC and LDV data compare closely. The flow is more distorted for the LDV measurements, while NCC show circular contours. The NCC produces slightly stronger recirculation regions (as given by negative axial velocity). Figure $16, Z=13 \mathrm{~mm}$, shows that the $\mathrm{NCC}$ is producing more uniform contours compared to the LDV measurements, but the values of the contours compare well. Figure 17, $Z=23 \mathrm{~mm}$, shows that the NCC computations are still producing nine strong recirculation regions, while the LDV measurements indicate that only four strong recirculation zones exist. At $Z=50 \mathrm{~mm}$, Figure 18 shows that flow features wash out for both NCC and LDV data. Both show a cross with four vortices, but the LDV features are slightly more shifted. Figure 19, $\mathrm{X}=0 \mathrm{~mm}$, show near the same contour lines. Again, the scales are different for the LDV measurements and the NCC predictions. As previously shown in Figure 8, LDV measurements indicate that the center swirler has a greater recirculation zone. Figure $20, X=19 \mathrm{~mm}$, the LDV data shows only one large recirculation zone, while the NCC computations predict that two large recirculation zones exist.

\section{(Text continues on page 15)}

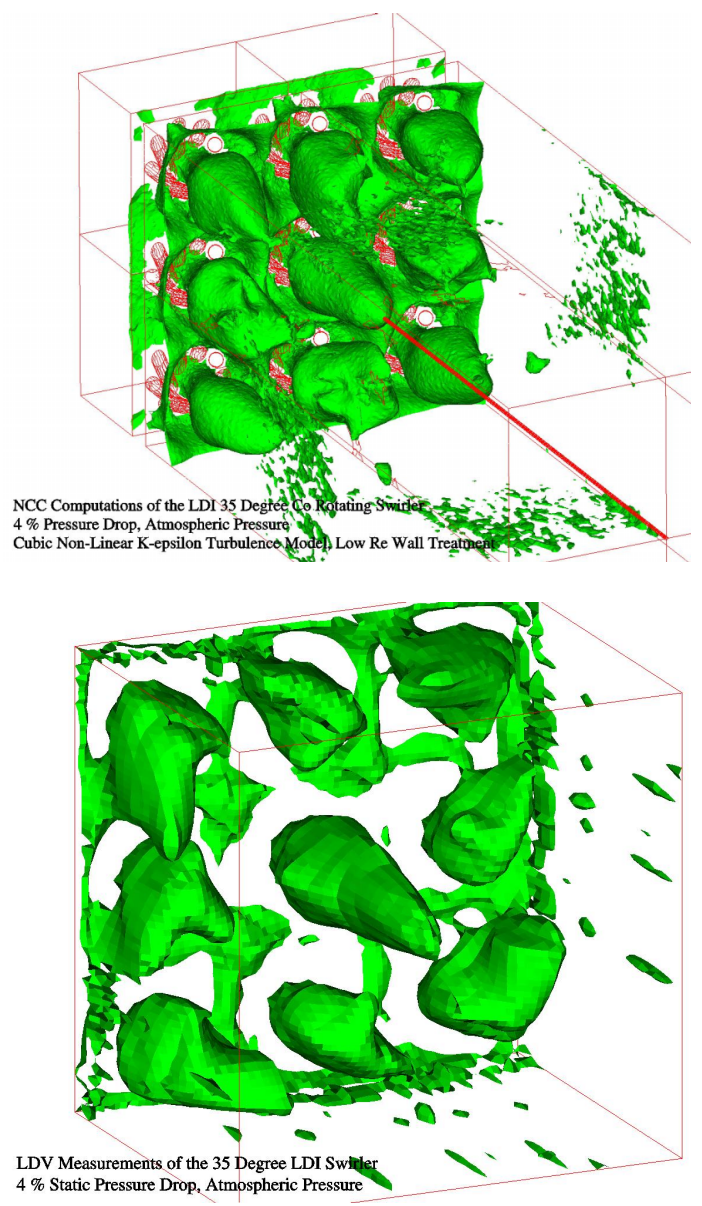

Figure 8 - Isosurface Comparisons between NCC Computations and LDV measurements for $\mathrm{W}$ Velocity $=0 \mathrm{~m} / \mathrm{s}$ 

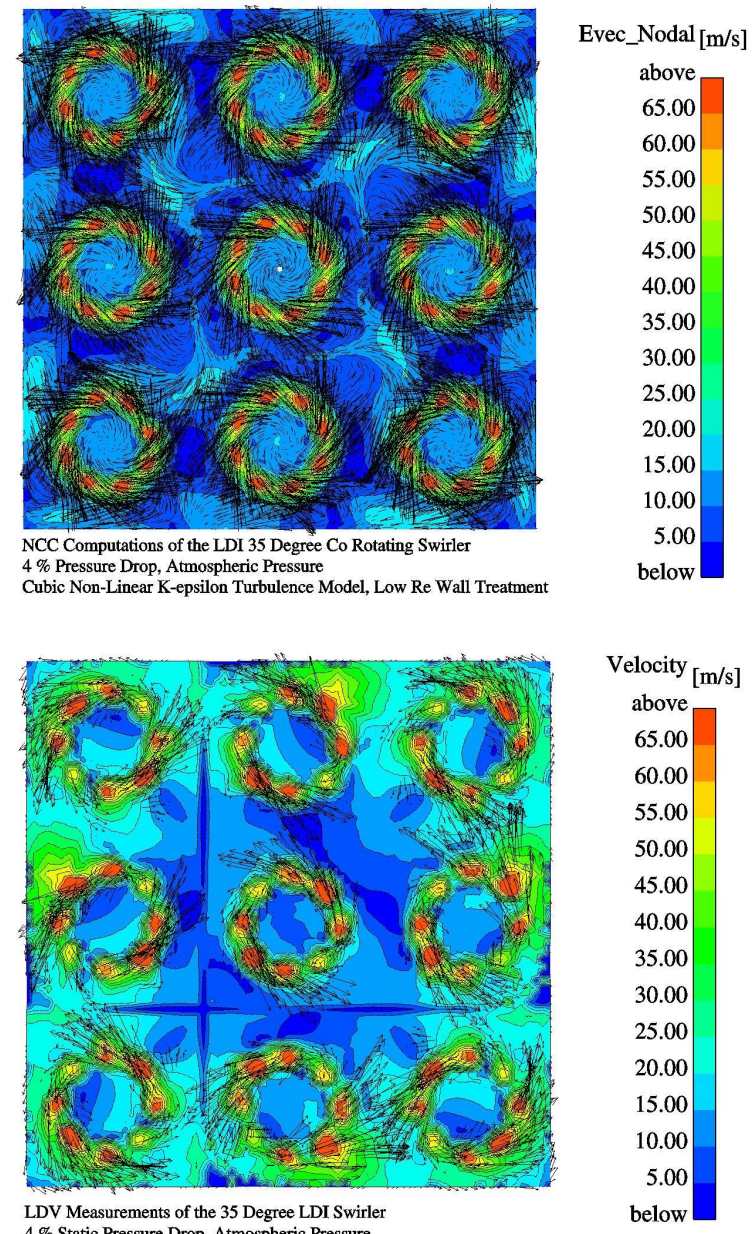

Figure 9 - Comparisons between NCC Computations and LDV Measurements, Vmag Contours and Velocity Vectors at the $Z=3 \mathrm{~mm}$ Plane

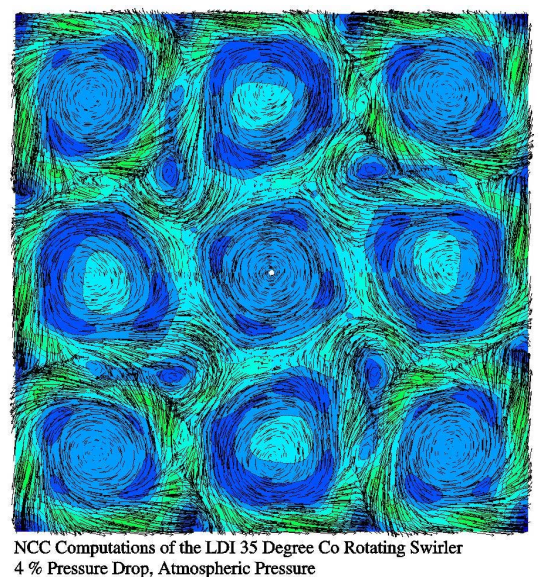

Evec_Nodal [m/s]

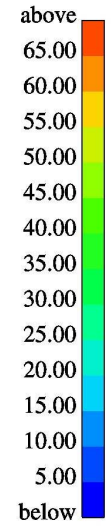

Cubic Non-Linear K-epsilon Turbulence Model, Low Re Wall Treatment
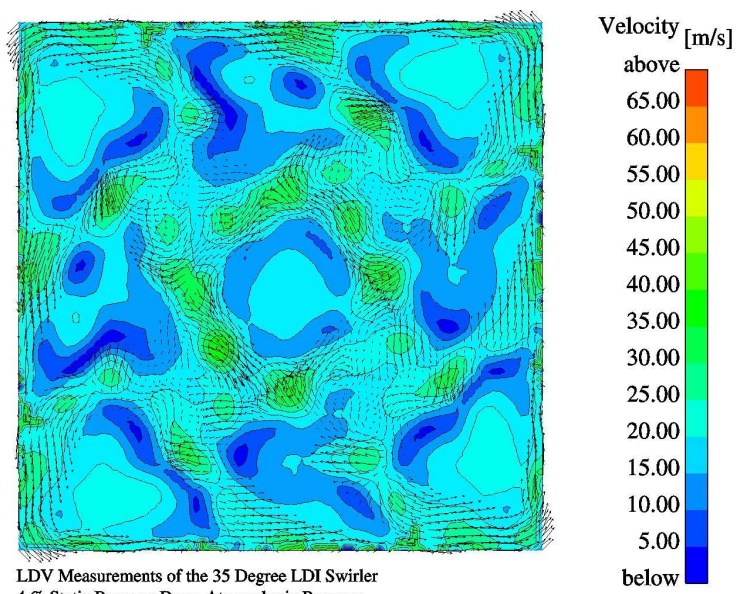

Figure 10 - Comparisons between NCC

Computations and LDV Measurements, Vmag Contours and Velocity Vectors at the $Z=13 \mathrm{~mm}$ Plane 

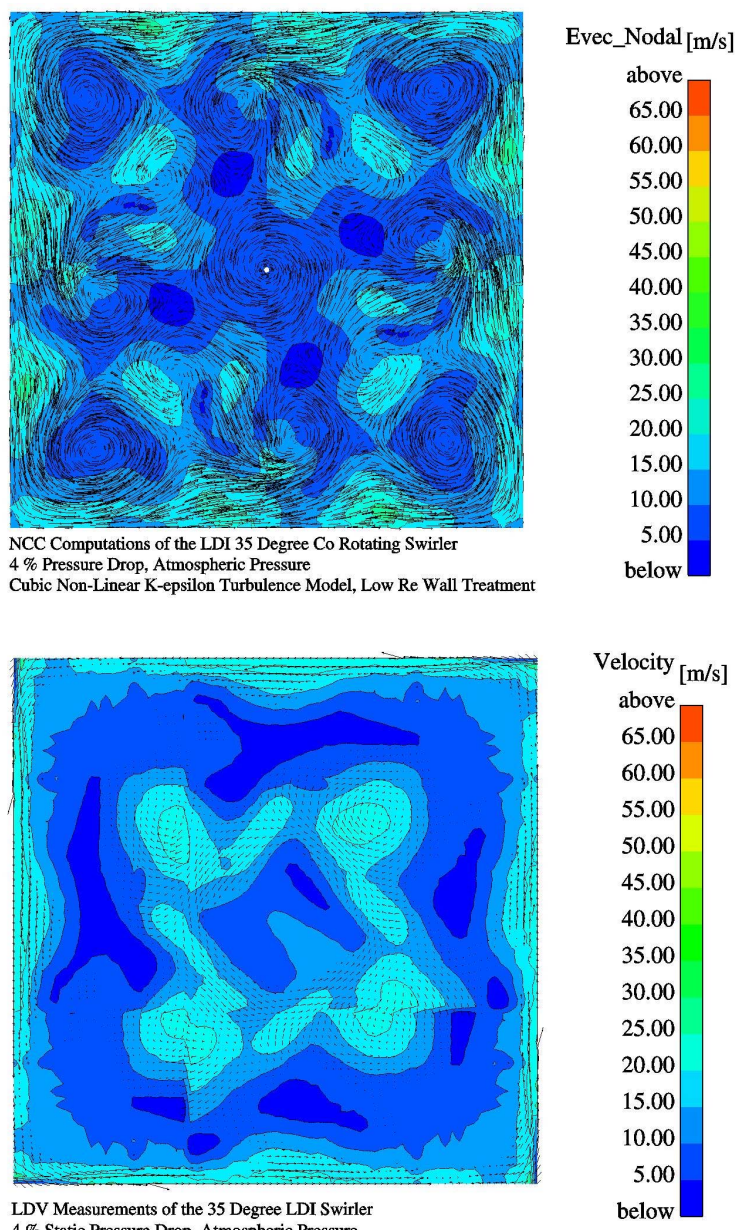

LDV Measurements of the 35 Degree LDI Swirle $4 \%$ Static Pressure Drop, Atmospheric Pressure

Figure 11 - Comparisons between NCC Computations and LDV Measurements, Vmag Contours and Velocity Vectors at the $Z=23 \mathrm{~mm}$ Plane

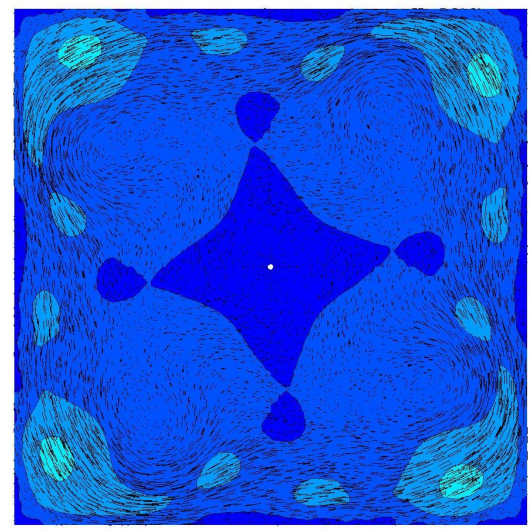

Evec_Nodal [m/s]

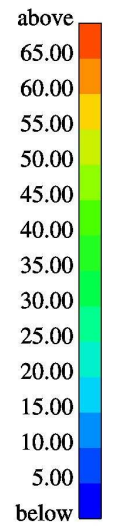

$4 \%$ Pressure Drop, Atmospheric Pressure
Cubic Non-Linear K-epsilon Turbulence Model, Low Re Wall Treatment below

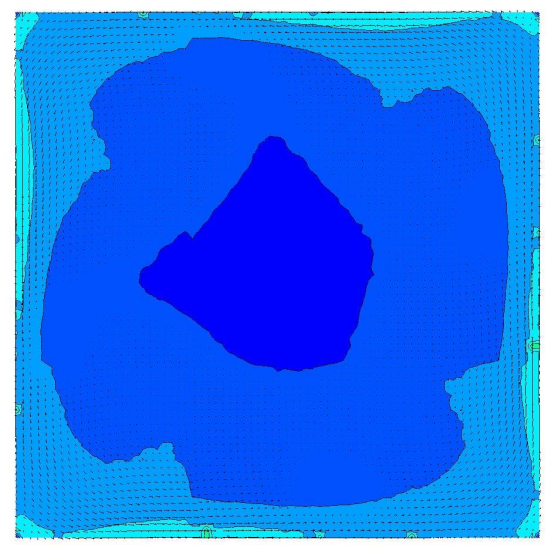

LDV Measurements of the 35 Degree LDI Swirler $4 \%$ Static Pressure Drop, Atmospheric Pressure

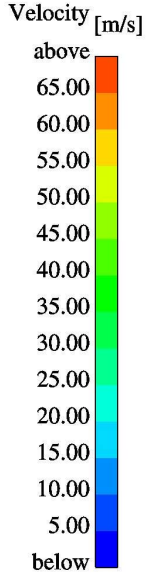

Figure 12 - Comparisons between NCC Computations and LDV Measurements, Vmag Contours and Velocity Vectors at the $Z=50 \mathrm{~mm}$ Plane 

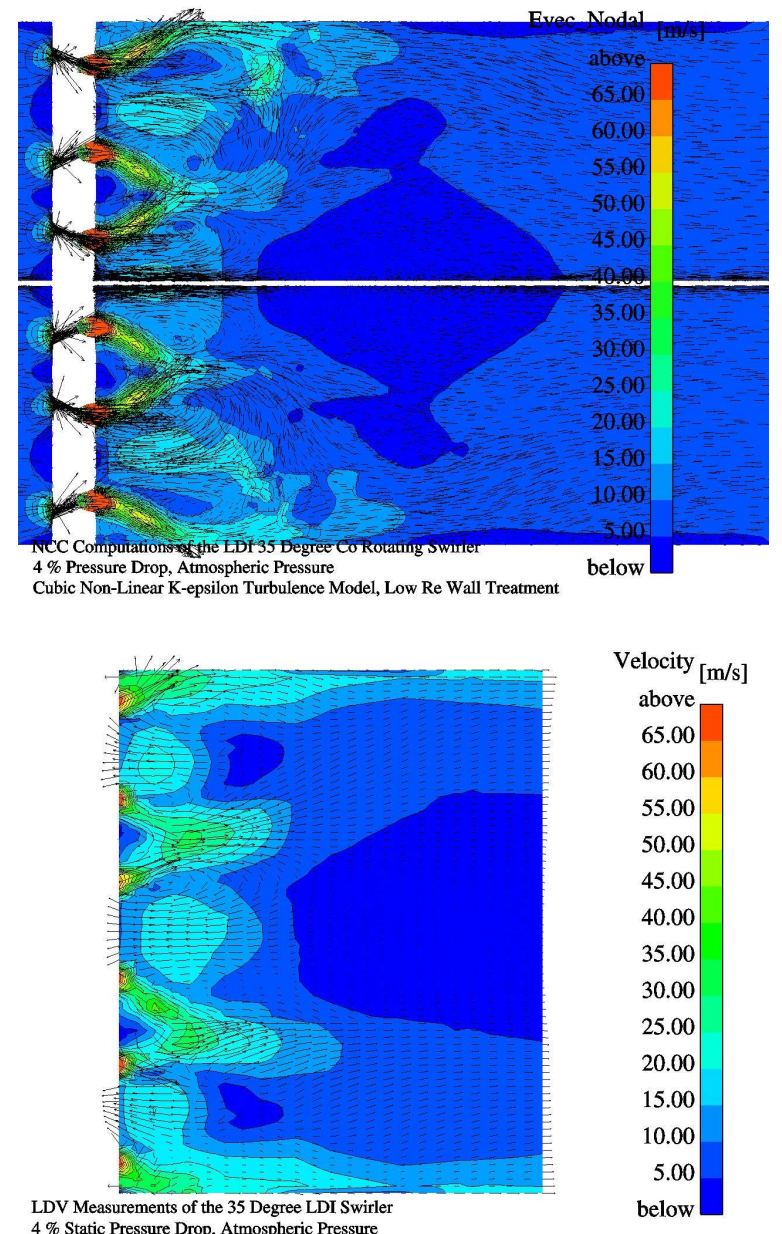

Figure 13 - Comparisons between NCC Computations and LDV Measurements, Vmag Contours and Velocity Vectors at the $X=0 \mathrm{~mm}$ Plane
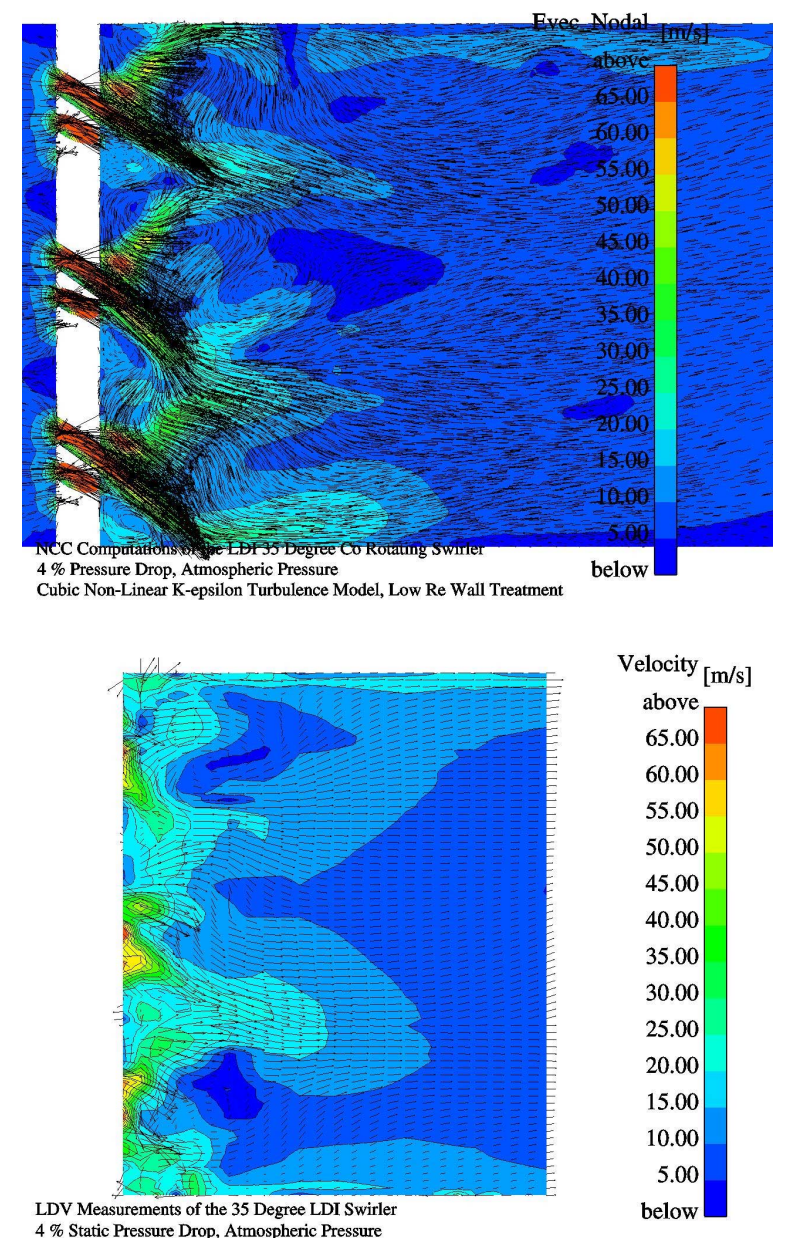

Figure 14 - Comparisons between NCC Computations and LDV Measurements, Vmag Contours and Velocity Vectors at the $X=19 \mathrm{~mm}$ Plane 


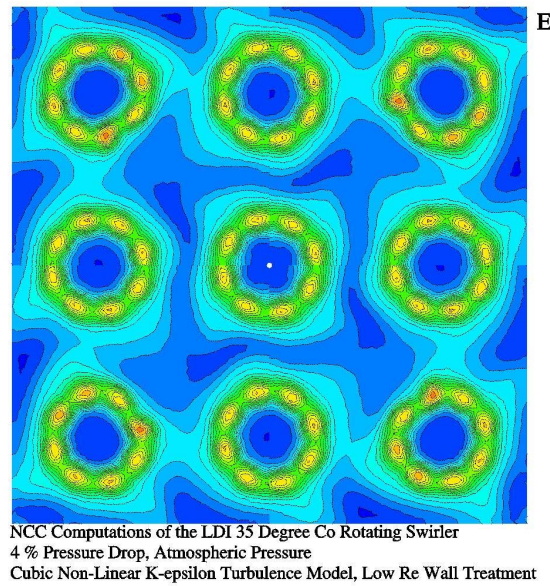

Evec_Nodal[Z] [m/s]

$$
\begin{array}{r}
\text { above } \\
65.00 \\
60.00 \\
55.00 \\
50.00 \\
45.00 \\
40.00 \\
35.00 \\
30.00 \\
25.00 \\
20.00 \\
15.00 \\
10.00 \\
5.00 \\
0.00 \\
-5.00 \\
-10.00 \\
-15.00 \\
\text { below }
\end{array}
$$

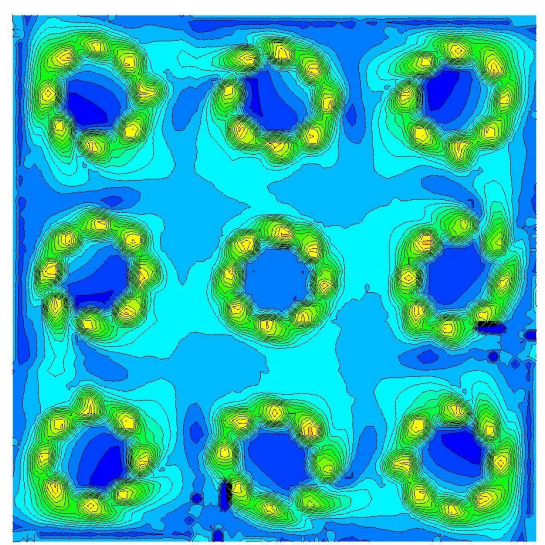

$$
\begin{array}{r}
\text { Velocity }[\mathrm{Z}][\mathrm{m} / \mathrm{s}] \\
\text { above } \\
65.00 \\
60.00 \\
55.00 \\
50.00 \\
45.00 \\
40.00 \\
35.00 \\
30.00 \\
25.00 \\
20.00 \\
15.00 \\
10.00 \\
5.00 \\
0.00 \\
-5.00 \\
-10.00 \\
-15.00 \\
\text { below }
\end{array}
$$

LDV Measurements of the 35 Degree LDI Swirler

Figure 15 - Comparisons between NCC

Computations and LDV Measurements, Axial (W) Velocity Contours at the $Z=3 \mathrm{~mm}$ Plane

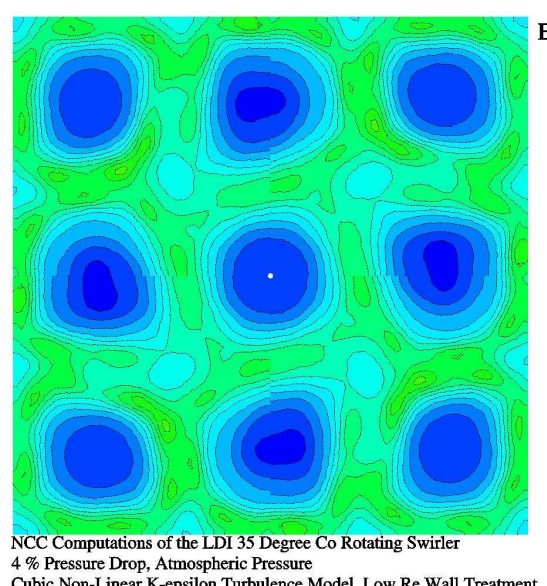

Evec_Nodal $[\mathrm{Z}][\mathrm{m} / \mathrm{s}]$

above
65.00
60.00
55.00
50.00
45.00
40.00
35.00
30.00
25.00
20.00
15.00
10.00
5.00
0.00
-5.00
-10.00
-15.00
below
$4 \%$ Pressure Drop, Atmospheric Pressure

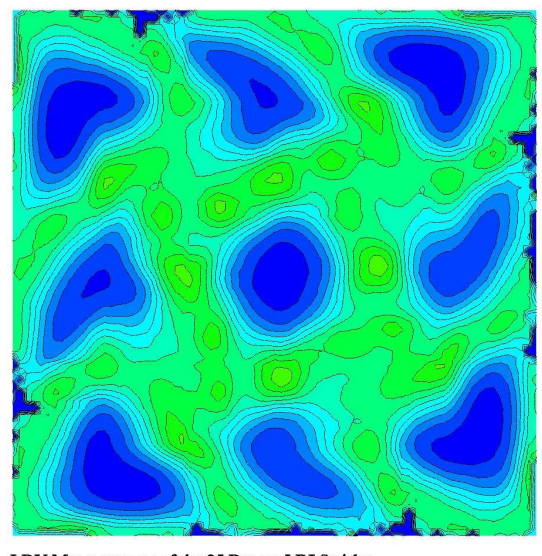

Velocity $[\mathrm{Z}][\mathrm{m} / \mathrm{s}]$ above 65.00 60.00 55.00 50.00

45.00 40.00 35.00

30.00 25.00 20.00 15.00 10.00 5.00

below

Figure 16 - Comparisons between NCC Computations and LDV Measurements, Axial (W) Velocity Contours at the $Z=13 \mathrm{~mm}$ Plane 


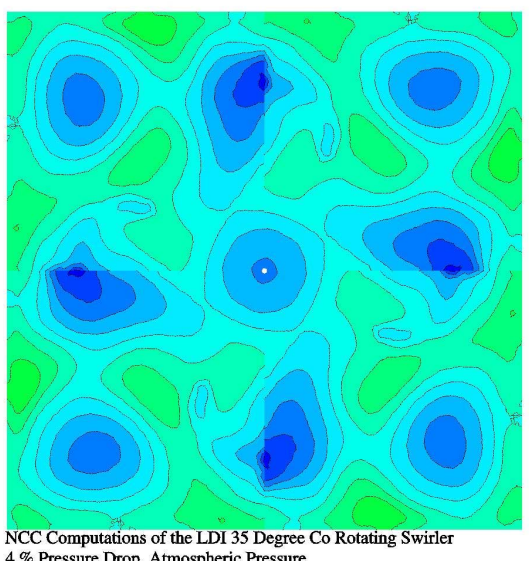

$4 \%$ Pressure Drop, Atmospheric Pressure

Cubic Non-Liner Kepsilo Tubulence Model, Low Re Wall Treatment

Evec_Nodal[Z] [m/s]

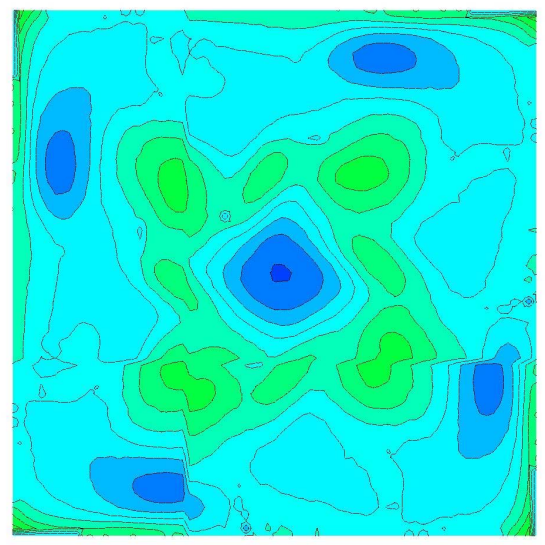

LDV Measurements of the 35 Degree LDI Swirler

$4 \%$ Static Pressure Drop, Atmospheric Pressure

Figure 17 - Comparisons between NCC

Computations and LDV Measurements, Axial (W) Velocity Contours at the $Z=23 \mathrm{~mm}$ Plane

$$
\begin{array}{r}
\text { above } \\
65.00 \\
60.00 \\
55.00 \\
50.00 \\
45.00 \\
40.00 \\
35.00 \\
30.00 \\
25.00 \\
20.00 \\
15.00 \\
10.00 \\
5.00 \\
0.00 \\
-5.00 \\
-10.00 \\
-15.00 \\
\text { below }
\end{array}
$$

$$
\begin{aligned}
& \text { Velocity }[\mathrm{Z}][\mathrm{m} / \mathrm{s}] \\
& \text { above } \\
& 65.00 \\
& 60.00 \\
& 55.00 \\
& 50.00 \\
& 45.00 \\
& 40.00 \\
& 35.00 \\
& 30.00 \\
& 25.00 \\
& 20.00 \\
& 15.00 \\
& 10.00 \\
& 5.00 \\
& 0.00 \\
& -5.00 \\
& -10.00 \\
& -15.00 \\
& \text { below }
\end{aligned}
$$

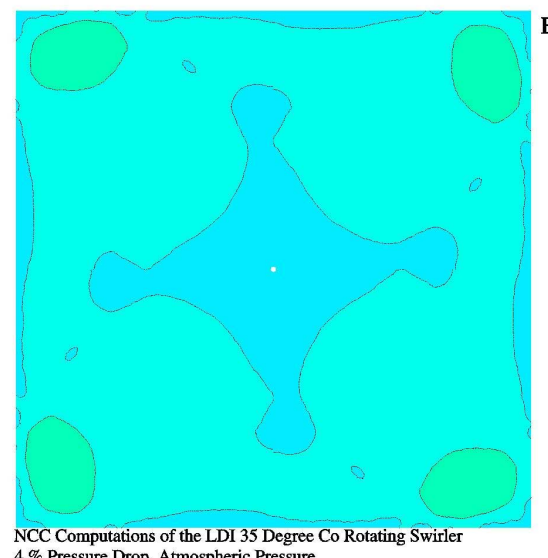

Evec_Nodal $[\mathrm{Z}][\mathrm{m} / \mathrm{s}]$

$4 \%$ Pressure Drop, Atmospheric Pressure

Cubic Non-Linear K-epsilon Turbulence Model, Low Re Wall Treatment

above
65.00
60.00
55.00
50.00
45.00
40.00
35.00
30.00
25.00
20.00
15.00
10.00
5.00
0.00
-5.00
-10.00
-15.00
below
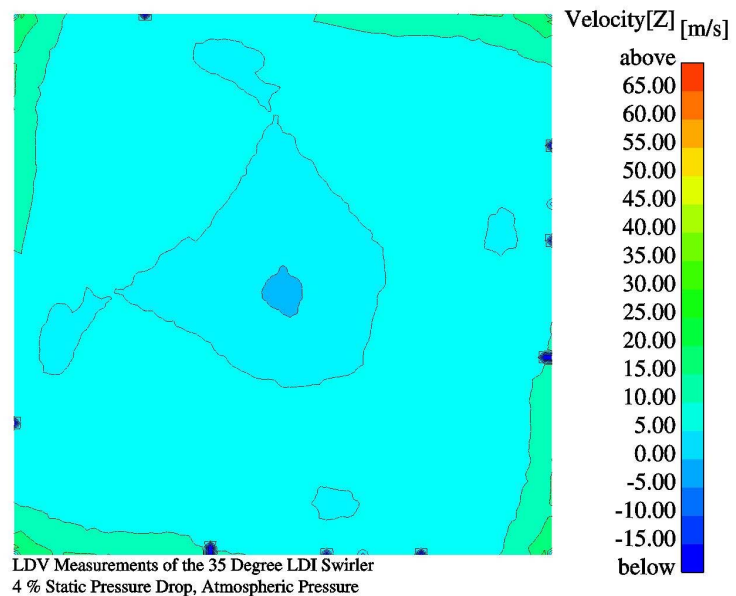

Figure 18 - Comparisons between NCC Computations and LDV Measurements, Axial (W) Velocity Contours at the $Z=50 \mathrm{~mm}$ Plane 

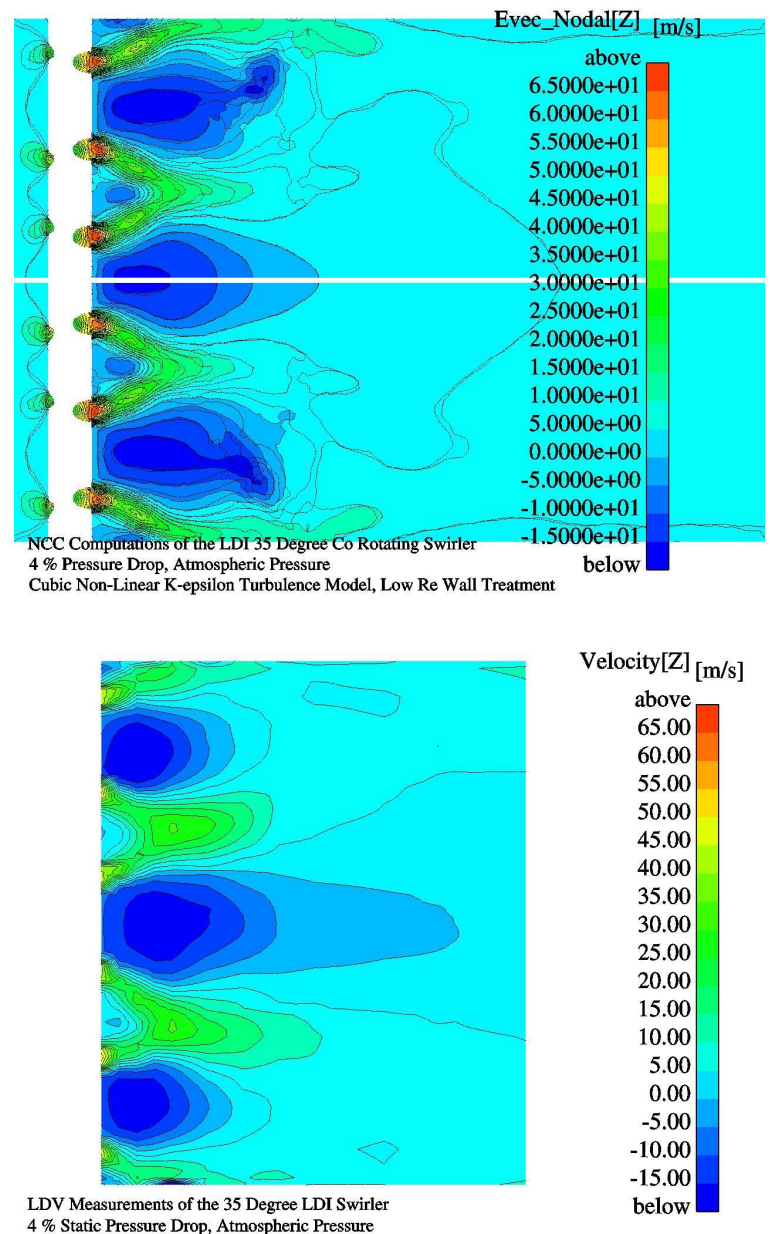

Figure 19 - Comparisons between NCC

Computations and LDV Measurements, Axial (W) Velocity Contours at the $X=0 \mathrm{~mm}$ Plane
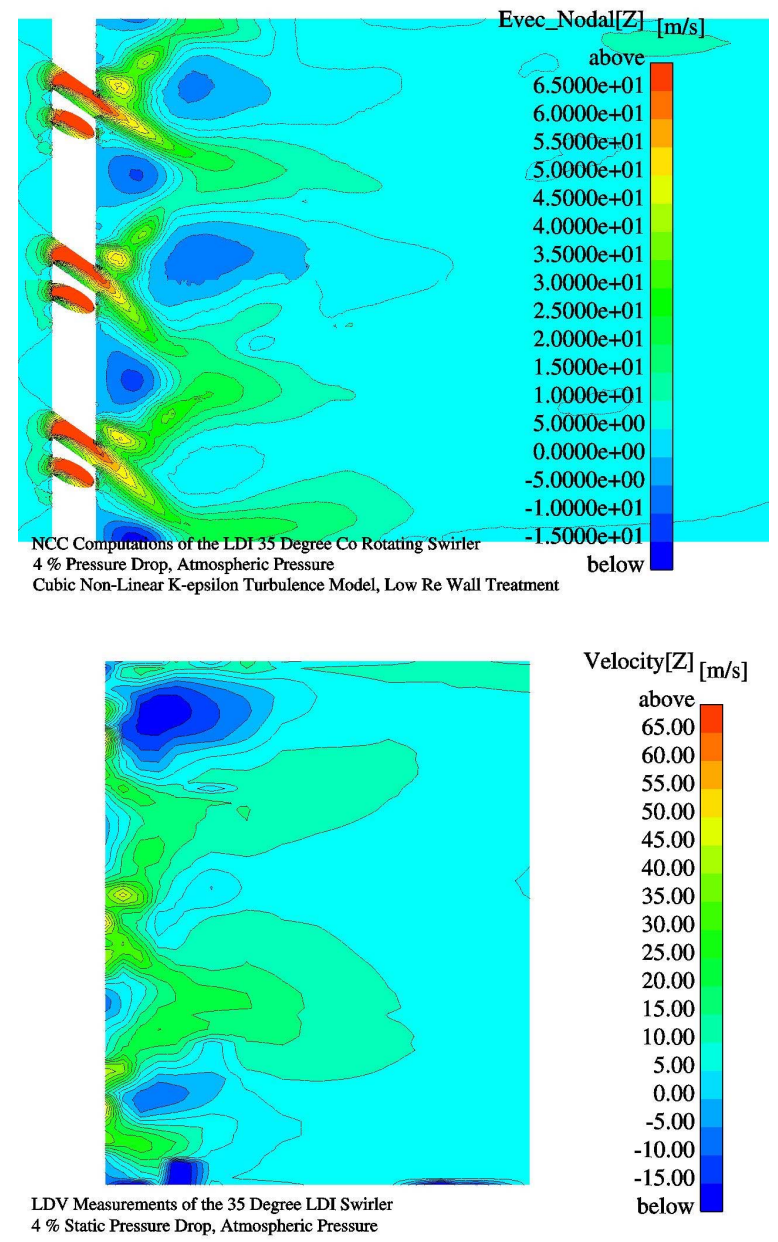

$$
\begin{aligned}
& \text { Velocity } \left.{ }^{[Z]}\right][\mathrm{m} / \mathrm{s}] \\
& \text { above } \\
& 65.00 \\
& 60.00 \\
& 55.00 \\
& 50.00 \\
& 45.00 \\
& 40.00 \\
& 35.00 \\
& 30.00 \\
& 25.00 \\
& 20.00 \\
& 15.00 \\
& 10.00 \\
& 5.00 \\
& 0.00 \\
& -5.00 \\
& -10.00 \\
& -15.00 \\
& \text { below }
\end{aligned}
$$
$4 \%$ Static Pressure Drop, Atmospheric Pressure

Figure 20 - Comparisons between NCC

Computations and LDV Measurements, Axial (W) Velocity Contours at the $X=19 \mathrm{~mm}$ Plane 

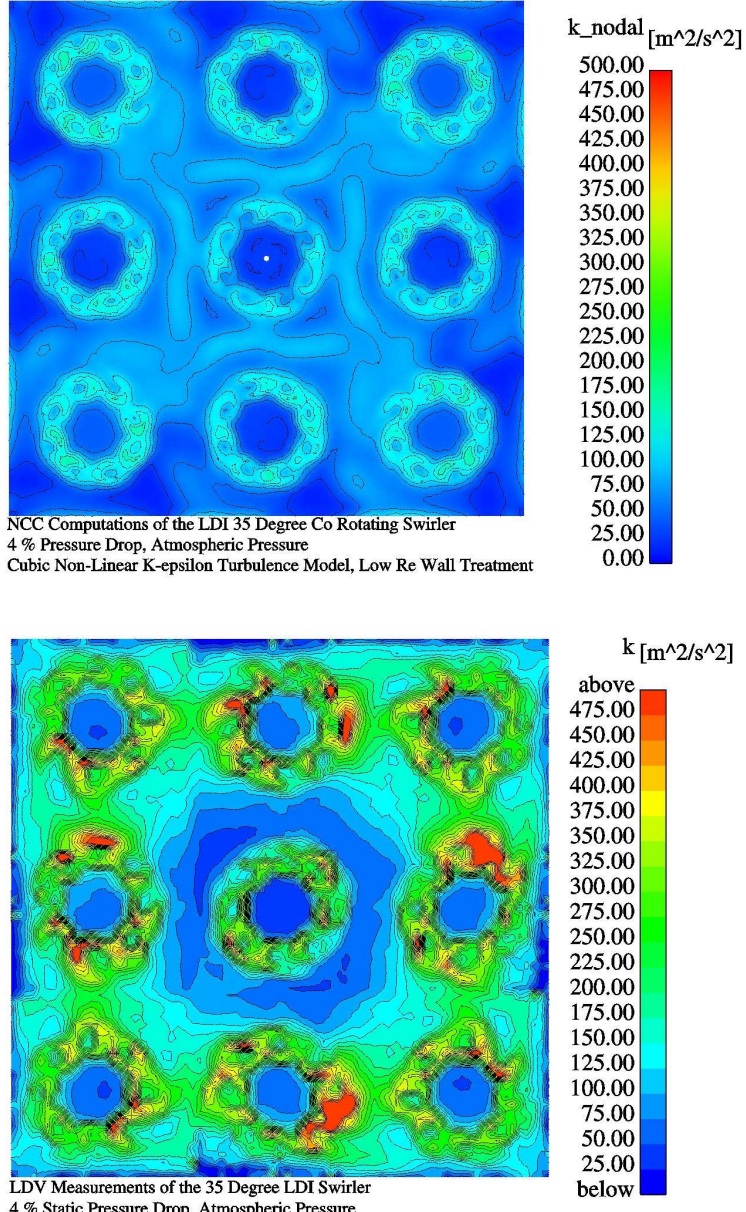

\begin{tabular}{l}
\multicolumn{2}{r}{$\mathrm{k}\left[\mathrm{m}^{\wedge} 2 / \mathrm{s}^{\wedge}\right.$} \\
above \\
475.00 \\
450.00 \\
425.00 \\
400.00 \\
375.00 \\
350.00 \\
325.00 \\
300.00 \\
275.00 \\
250.00 \\
225.00 \\
200.00 \\
175.00 \\
150.00 \\
125.00 \\
100.00 \\
75.00 \\
50.00 \\
25.00 \\
below
\end{tabular}

Figure 21 - Comparisons between NCC Computations and LDV Measurements, Turbulent Kinetic Energy (k) at the $Z=3 \mathrm{~mm}$ Plane
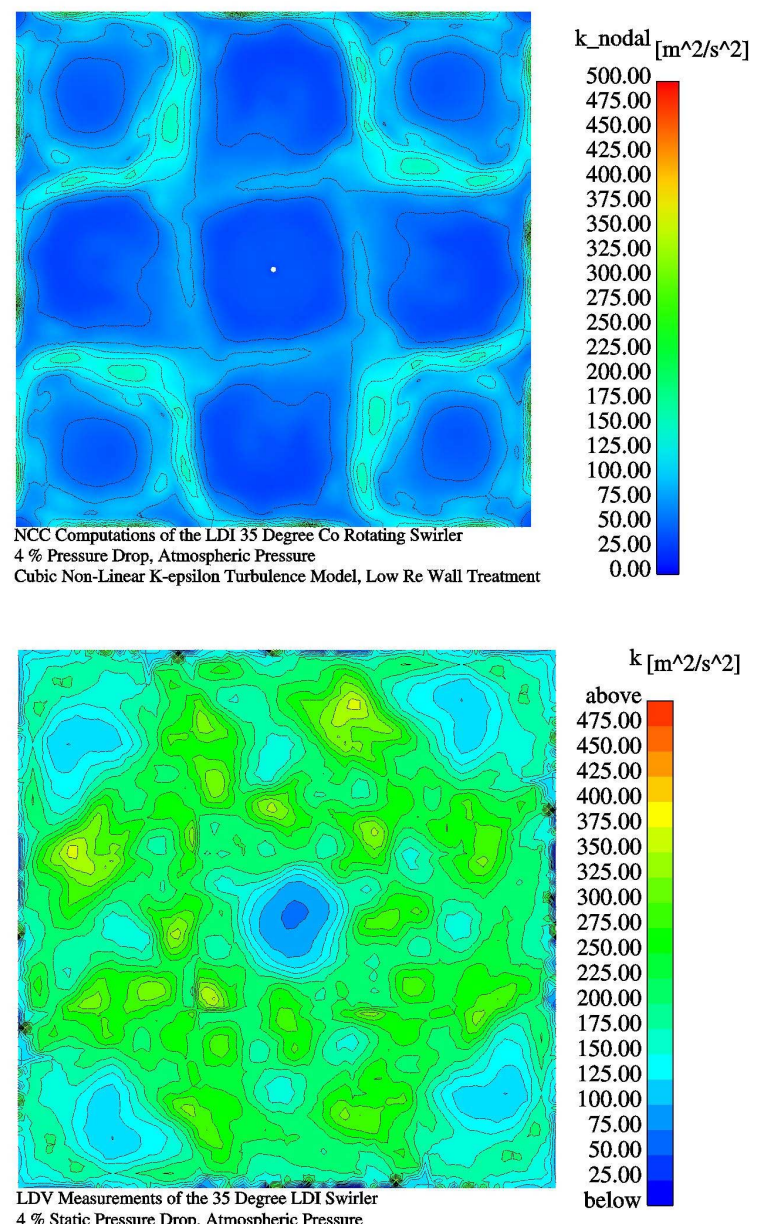

$$
\begin{array}{r}
350.00 \\
325.00 \\
300.00 \\
275.00 \\
250.00 \\
225.00 \\
200.00 \\
175.00 \\
150.00 \\
125.00 \\
100.00 \\
75.00 \\
50.00 \\
25.00 \\
\text { below }
\end{array}
$$$$
\mathrm{k}\left[\mathrm{m}^{\wedge} 2 / \mathrm{s}^{\wedge} 2\right]
$$$$
\text { above }
$$$$
475.00
$$$$
450.00
$$$$
425.00
$$$$
\begin{aligned}
& 400.00 \\
& 375.00
\end{aligned}
$$$$
325.00
$$$$
300.00
$$$$
200.00
$$$$
175.00
$$$$
150.00
$$

Figure 22 - Comparisons between NCC Computations and LDV Measurements, Turbulent Kinetic Energy (k) at the $Z=13 \mathrm{~mm}$ Plane 


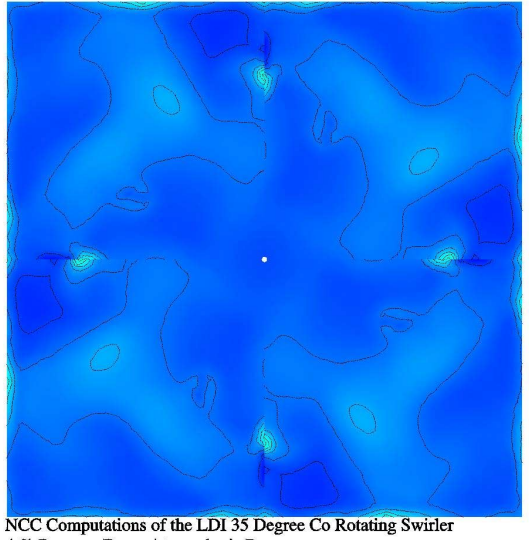
$4 \%$ Pressure Drop, Atmospheric Pressure Cubic Non-Linear K-epsilon Turbulence Model, Low Re Wall Treatment

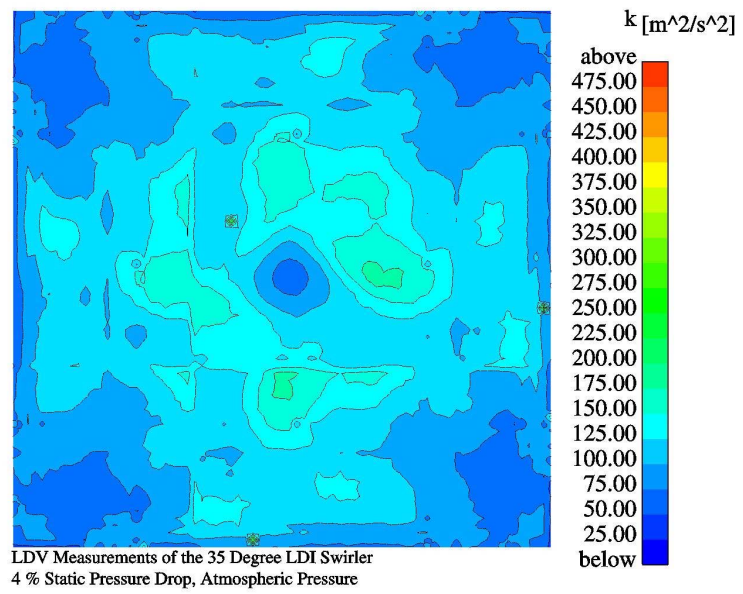

Figure 23 - Comparisons between NCC Computations and LDV Measurements,
Turbulent Kinetic Energy (k) at the $Z=23 \mathrm{~mm}$ Computations and LDV Measurements,
Turbulent Kinetic Energy (k) at the $Z=\mathbf{2 3 m m}$ Plane

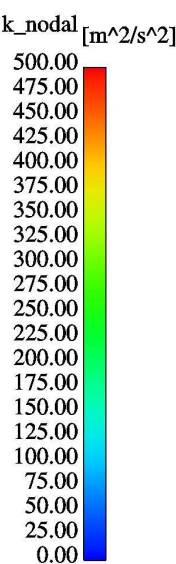

$k$

$$
\begin{array}{r}
475.00 \\
450.00 \\
425.00 \\
400.00 \\
375.00 \\
350.00 \\
325.00 \\
300.00 \\
275.00 \\
250.00 \\
225.00 \\
200.00 \\
175.00 \\
150.00 \\
125.00 \\
100.00 \\
75.00 \\
50.00 \\
25.00 \\
\text { below }
\end{array}
$$

LDV Measurements of the 35 Degree LDI Swir

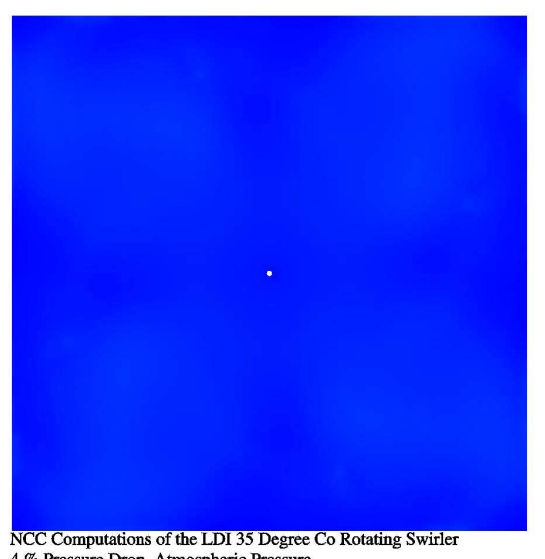

$4 \%$ Pressure Drop, Atmospheric Pressure
Cubic Non-Linear K-epsilon Turbulence Model, Low Re Wall Treatment
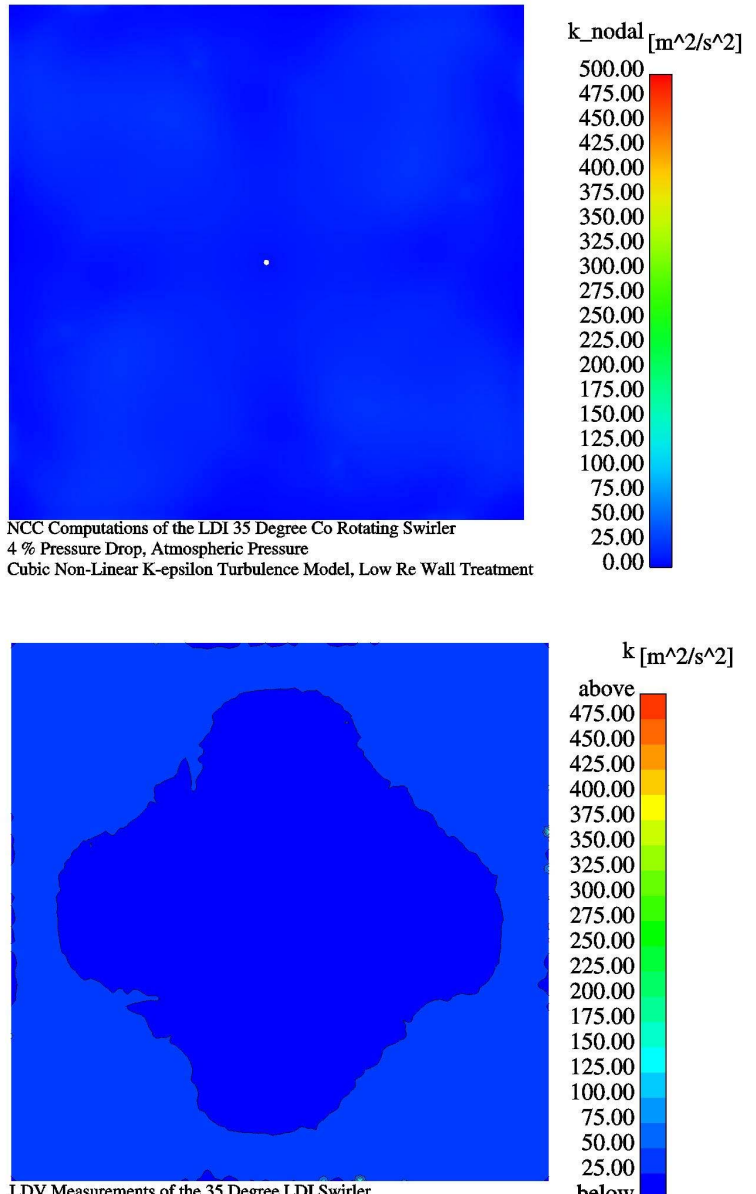

$\mathrm{k}\left[\mathrm{m}^{\wedge} 2 / \mathrm{s}^{\wedge} 2\right]$

above

475.00

450.00

425.00

400.00

375.00

350.00

325.00

300.00

275.00

250.00

225.00

200.00

175.00

150.00

125.00

125.00

75.00

50.00

25.00

below

$4 \%$ Static Pressure Drop, Atmospheric Pressire

Figure 24 - Comparisons between NCC Computations and LDV Measurements,

Turbulent Kinetic Energy (k) at the $Z=50 \mathrm{~mm}$ Plane 

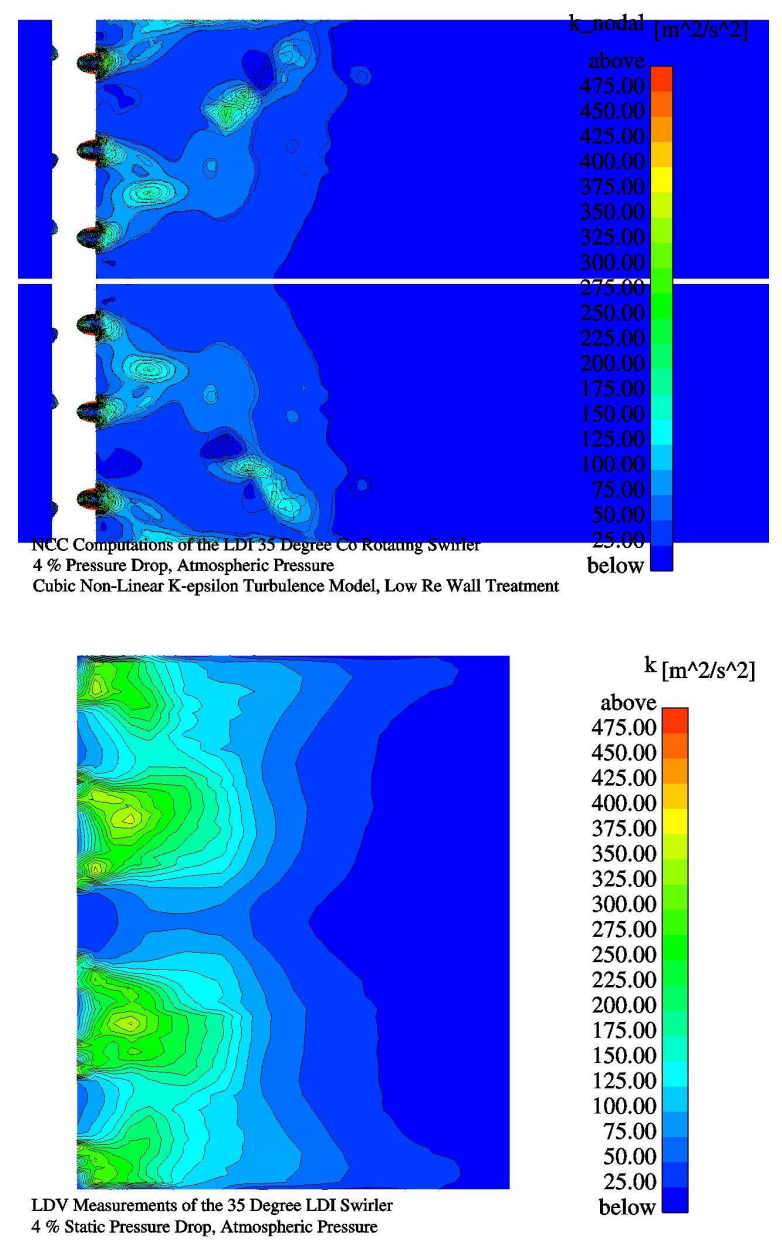

Figure 25 - Comparisons between NCC Computations and LDV Measurements, Turbulent Kinetic Energy (k) at the $X=0 \mathrm{~mm}$ Plane
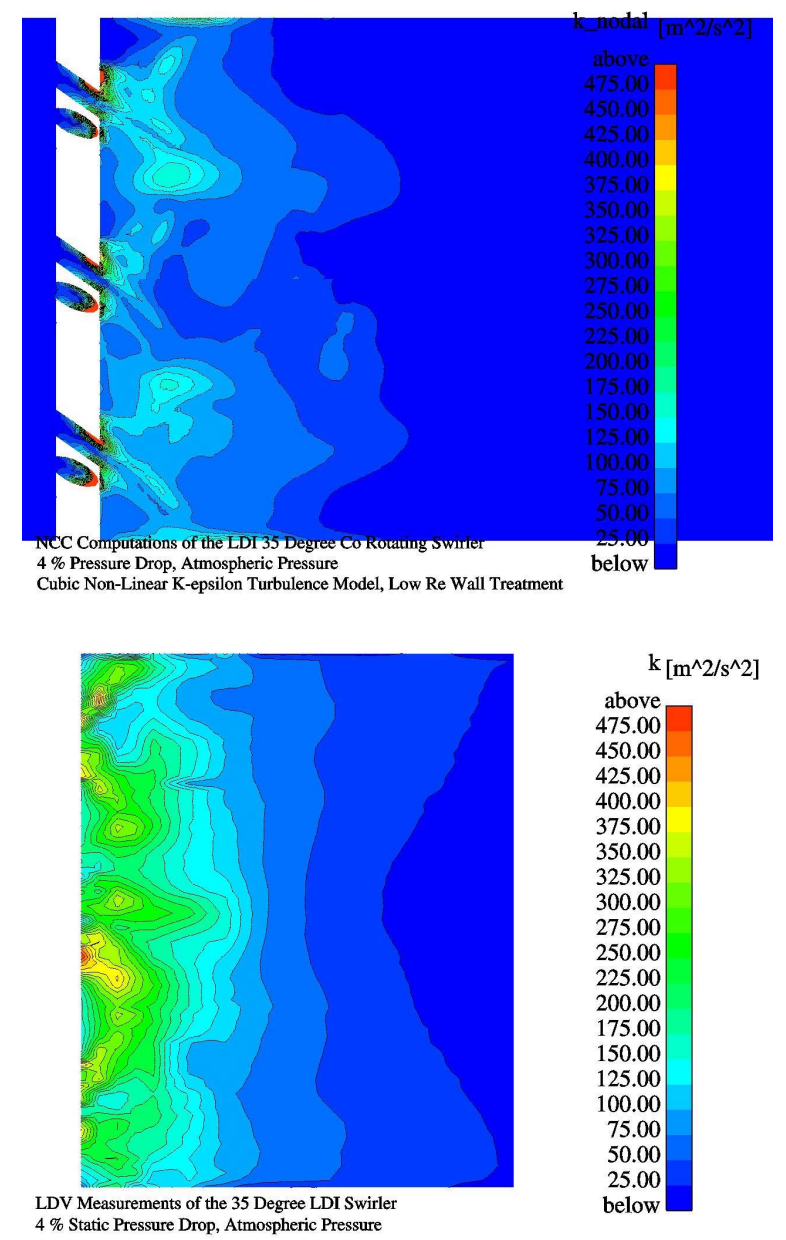

Figure 26 - Comparisons between NCC Computations and LDV Measurements, Turbulent Kinetic Energy (K) at the $X=19 \mathrm{~mm}$ Plane 
At this time, NCC cannot report Reynolds stress components. LDV RMS measurements can be easily converted to $\mathrm{k}$, the turbulent kinetic energy, by Equation (1). The NCC computes $\mathrm{k}$ as part of the $\mathrm{k}-$ epsilon model.

Equation (1)

$k=\frac{1}{2}\left(U_{r m s}^{2}+V_{r m s}^{2}+W_{r m s}^{2}\right)$

Figure 21 through Figure 26 show contours of turbulent kinetic energy. Figure $21, \mathrm{Z}=3 \mathrm{~mm}$, shows that $\mathrm{NCC}$ underpredicts the turbulent kinetic energy by $50 \%$ compared to the LDV measurements. The shape of the contours is similar. Figure $22, \mathrm{Z}=13 \mathrm{~mm}$, the NCC calculations underpredict the turbulent kinetic energy, and the contours are different. The LDV measurements show the turbulent kinetic energy has an even nature, which the NCC calculations do not show. Looking at Figure $23, Z=23 \mathrm{~mm}$, the LDV measurements indicate that the turbulent kinetic energy does not vary much at this plane. NCC computations underpredict the turbulent energy and do not show the same contour lines. At $\mathrm{Z}=50 \mathrm{~mm}$, Figure 24 show that the turbulent kinetic energy, has dissipated for both the NCC computations and the LDV measurements. Figure 25 and Figure 26, X $=0 \mathrm{~mm}$ and $19 \mathrm{~mm}$, show once again that NCC calculations underpredict the turbulent energy by approximately $50 \%$ and generally do not show the even nature regarding this turbulent flow. The NCC calculations and LDV measurements show that around $50 \mathrm{~mm}$, the turbulent kinetic energy does dissipate to nearly zero.

Contour and Vector plots present good overall comparisons but do not quantitatively compare the NCC and LDV data. For this reason, line plots are extracted from both data sets. Figure 27 shows where the line plots were extracted. Figures 28 through 31 compare velocity magnitude at line plots 1,2 , and 3 . Line Plot 1 is a line extracted axially $(\mathrm{Z})$ at $\mathrm{X}=$ $25.4 \mathrm{~mm}, Y=-25.4 \mathrm{~mm}$ (in the center of a corner swirler). Line Plot 2 is a line extracted axially at $\mathrm{X}=$ $12.7 \mathrm{~mm}, \mathrm{Y}=-12.7 \mathrm{~mm}$ (one of four positions between the swirlers). Line Plot 3 is a XY diagonal line at the $\mathrm{Z}$ $=23 \mathrm{~mm}$ plane (at this plane the NCC computations and LDV differ). Figure 28 shows a comparison for the velocity magnitude for Line Plots 1-3. At Line Plot 1, the NCC predicts the general trend for the velocity magnitude, but at $5-10 \mathrm{~mm}$ and $25-35 \mathrm{~mm}$, the NCC is off by 30 to $50 \%$. For Line Plot 2, the NCC shows the overall trend, but does not show the flow structure in the $3-10 \mathrm{~mm}$ region. The NCC generally over predicts values by $50 \%$ from $10-25 \mathrm{~mm}$. Past this region, the NCC generally agrees within $20 \%$ of the LDV data. At Line Plot 3, the NCC computations seem to smear out flow structures compared to the LDV measurements. The NCC is generally within $20 \%$ of the LDV data. Figure 29 shows a comparison for the $U$ velocity at Line Plots $1-3$. Line Plot 1 shows that the NCC predicts the same flow structure $10 \mathrm{~mm}$ before the LDV measurements. Values are off by more than $50 \%$ in the $5-25 \mathrm{~mm}$ region, with the NCC agreeing within $20 \%$ after $25 \mathrm{~m}$. Line Plot 2 shows the same general trend, disagreeing in the $10-20 \mathrm{~mm}$ region. Except for this region, the NCC is within $20 \%$ of the experimental values. At Line Plot 3, the NCC shows the general trend, with values within $20 \%$ of the smooth regions. In the $22-35 \mathrm{~mm}$ region, a region of a strong gradients, the NCC disagrees by more than $50 \%$. Figure 30 shows a comparison for the $\mathrm{V}$ velocity at Line Plots $1-3$. At Line Plot 1, the trend the NCC predicts is poor. Values are off $30-50 \%$ near the swirler exit and diverge downstream. Line Plot 2 shows a general trend. From $5-40 \mathrm{~mm}$, the $\mathrm{V}$ velocity is underpredicted $30-50 \%$. The comparison between the NCC computations and LDV measurements gets better past $40 \mathrm{~mm}$. For Line Plot 3, a trend is not shown. The NCC values seem to be out of phase with the LDV data. Figure 31 shows a comparison for the $\mathrm{W}$ velocity for Line Plots $1-3$. For Line Plot 1 , the agreement is very good. For the entire plot, the NCC calculations are within $10-20 \%$ of the LDV measurements. Line Plot 2 shows good agreement within $20 \%$ of the LDV data. In the $20-$ $30 \mathrm{~mm}$ region, the comparison is within $30-50 \%$. Line Plot 3 shows a general trend, but the NCC does not show all of the flow structures. At $15-25 \mathrm{~mm}$, the $\mathrm{NCC}$ is off by more than $30-50 \%$, and at $35-45 \mathrm{~mm}$, it is off by more than $50 \%$.

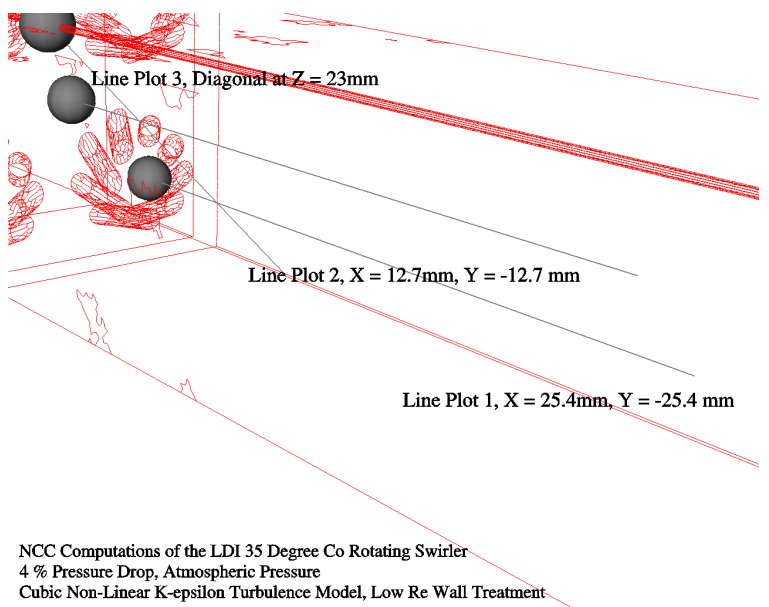

Figure 27 - Location of the Line Plots 


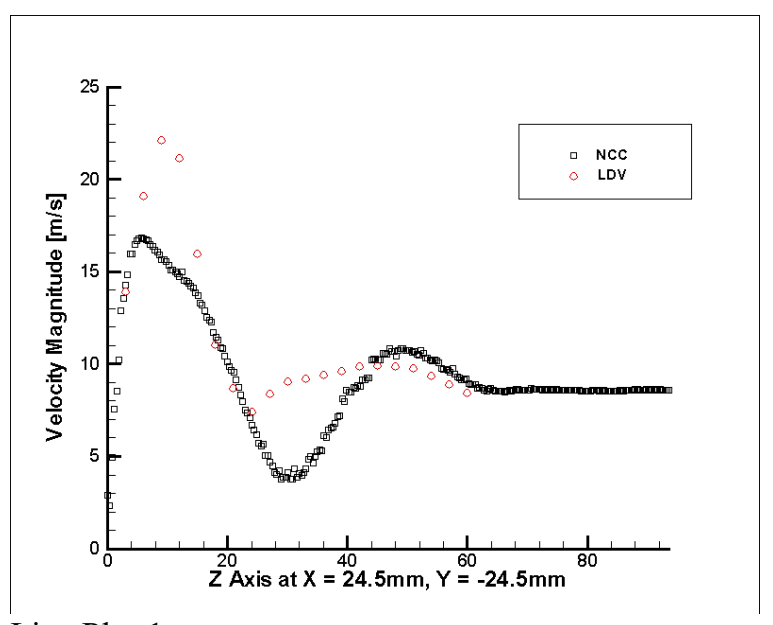

Line Plot 1

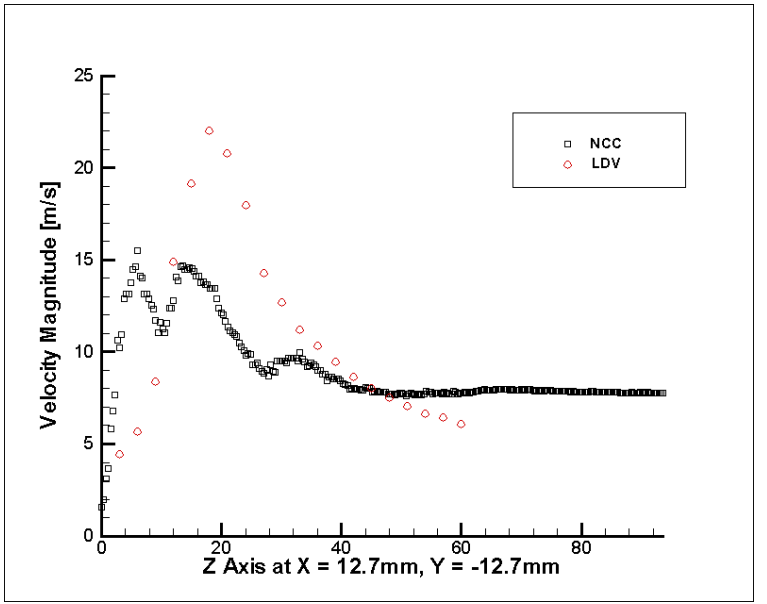

Line Plot 2

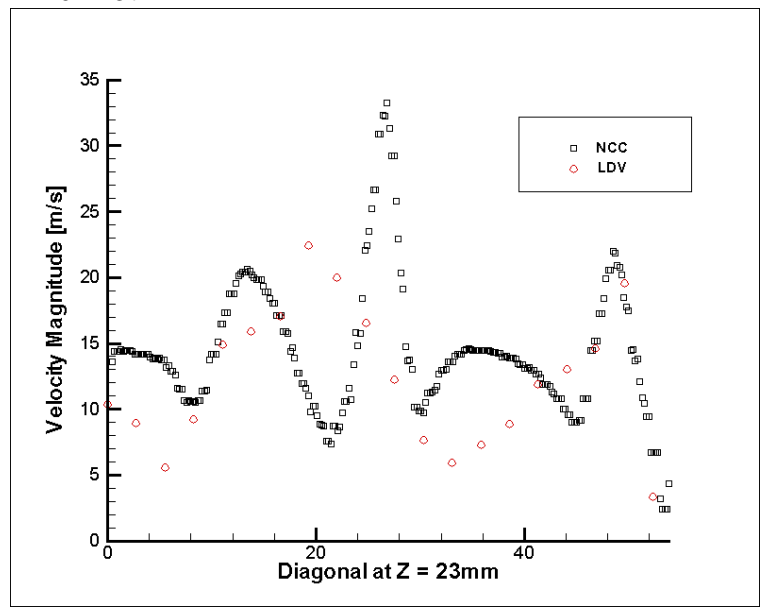

Line Plot 3

Figure 28 - Comparisons between NCC Computations and LDV Measurements, Velocity Magnitude at Line Plots 1, 2, and 3

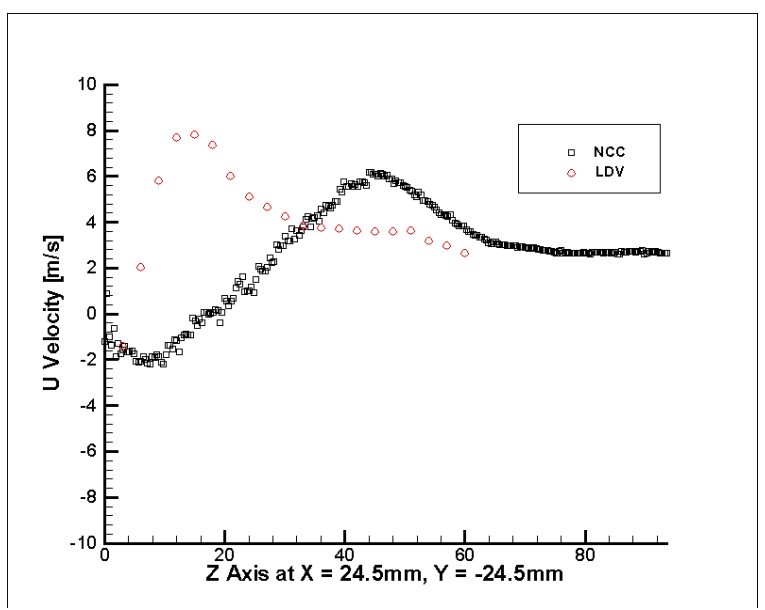

Line Plot 1

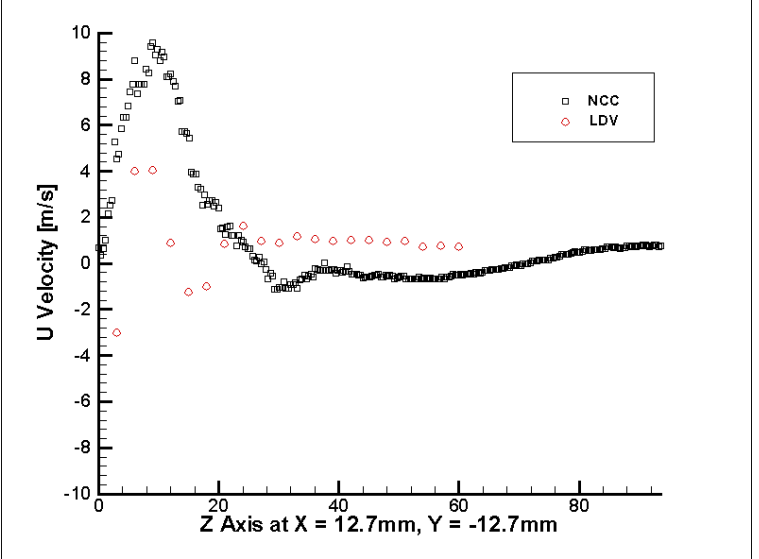

Line Plot 2

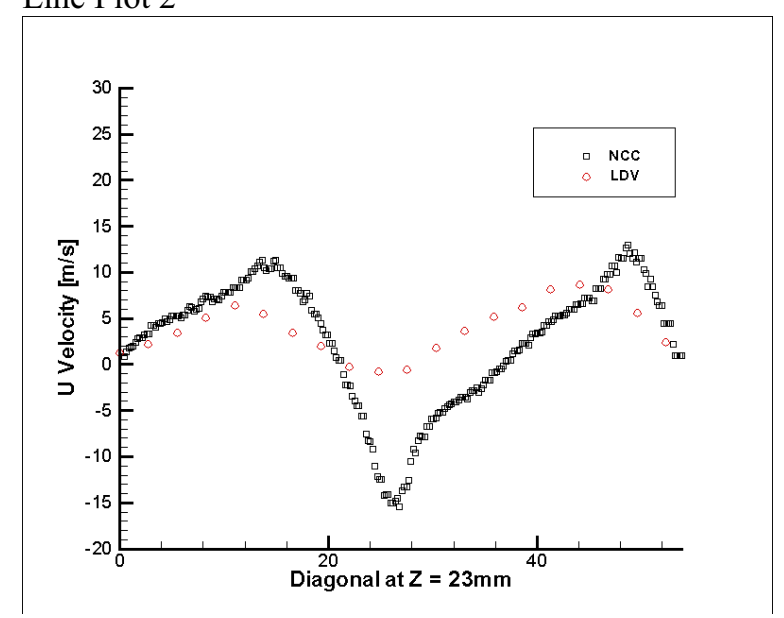

Line Plot 3

Figure 29 - Comparisons between NCC

Computations and LDV Measurements, $U$ Velocity at Line Plots 1, 2, and 3 


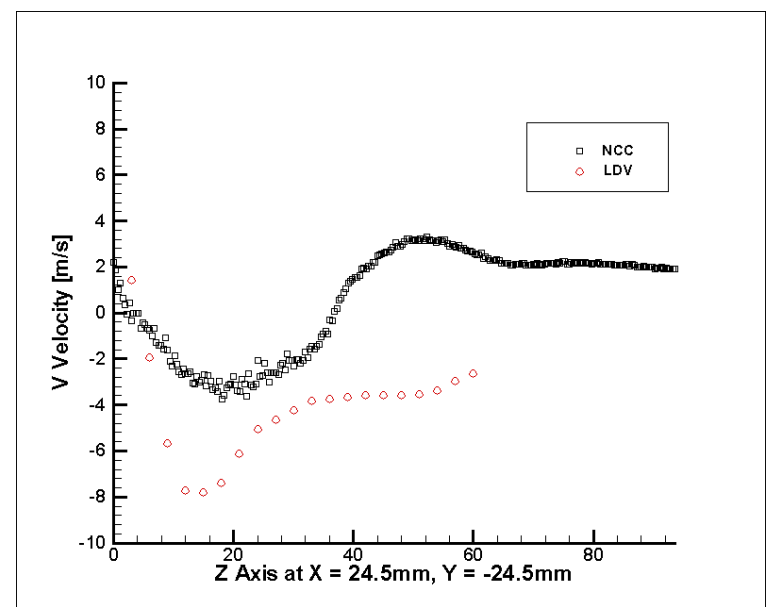

Line Plot 1

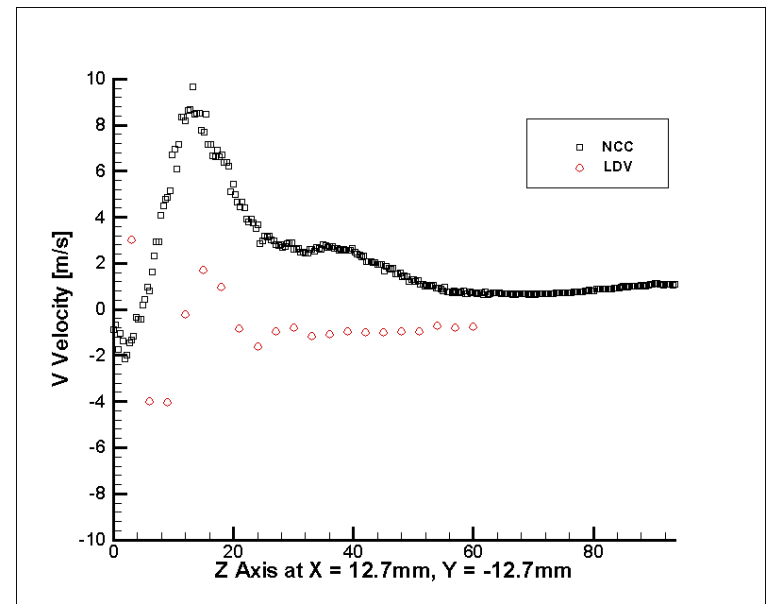

Line Plot 2

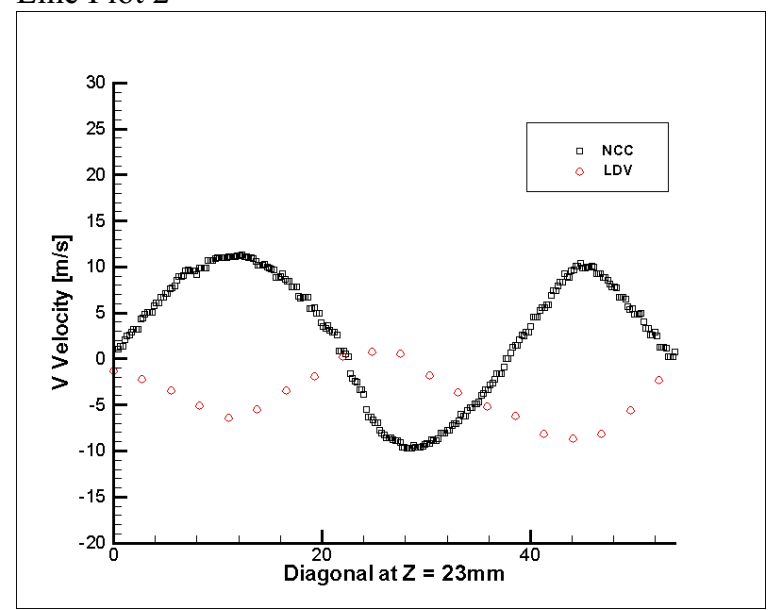

Line Plot 3

Figure 30 - Comparisons between NCC Computations and LDV Measurements, V Velocity at Line Plots 1, 2, and 3

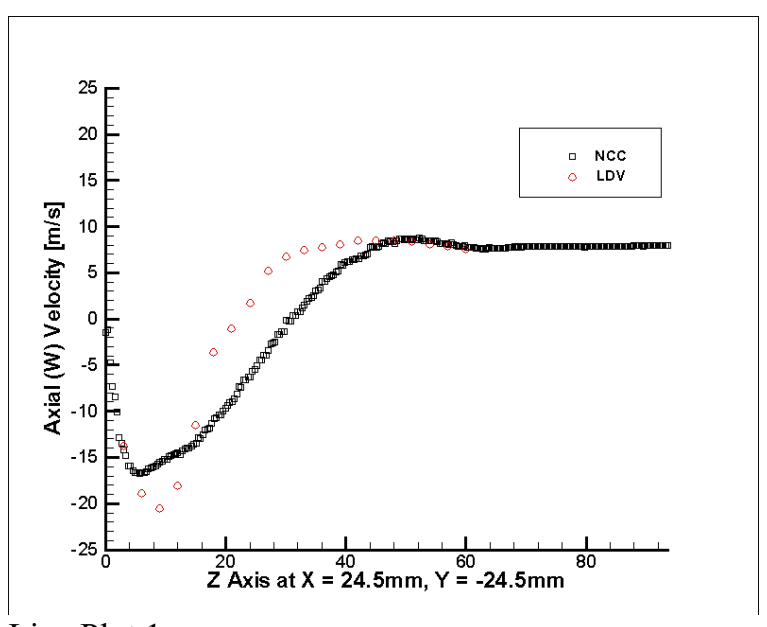

Line Plot 1

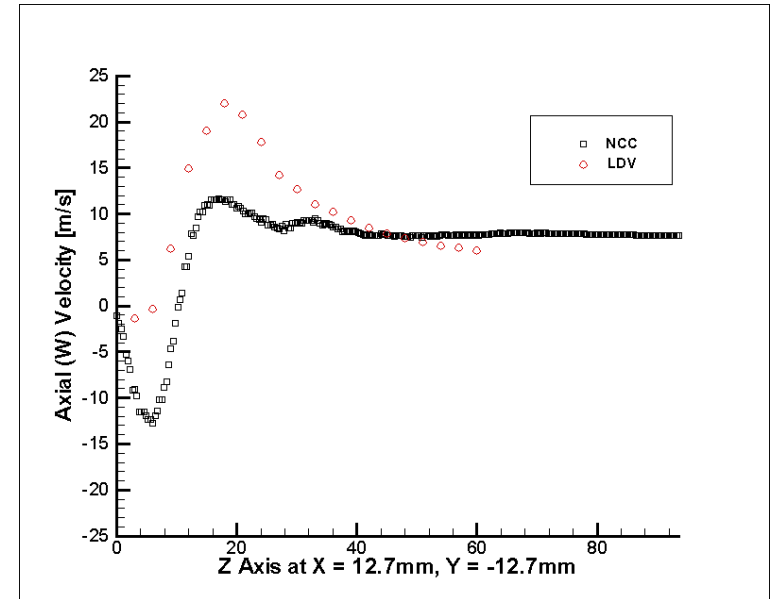

Line Plot 2

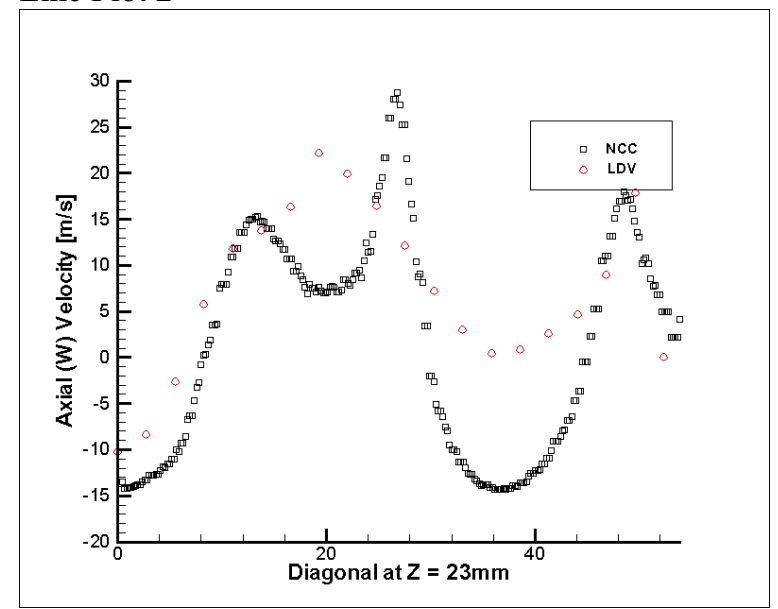

Line Plot 3

Figure 31 - Comparisons between NCC Computations and LDV Measurements, W Velocity at Line Plots 1, 2, and 3 


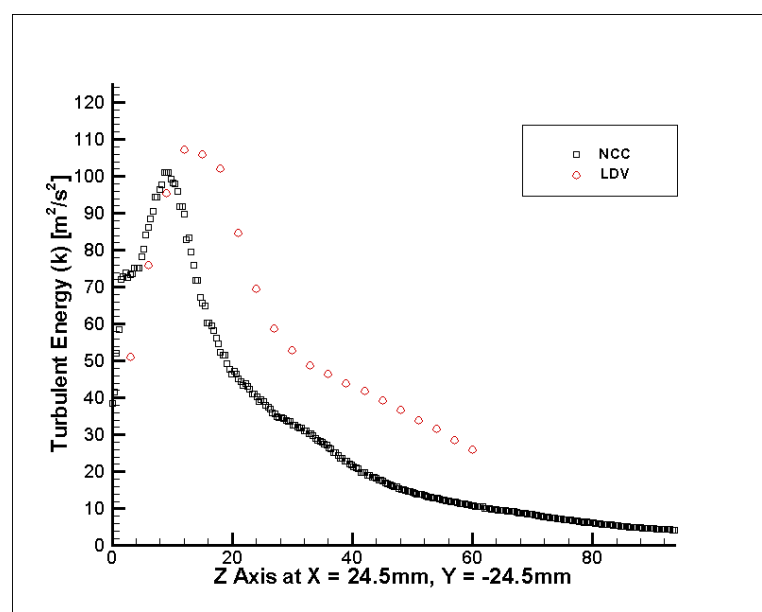

Line Plot 1
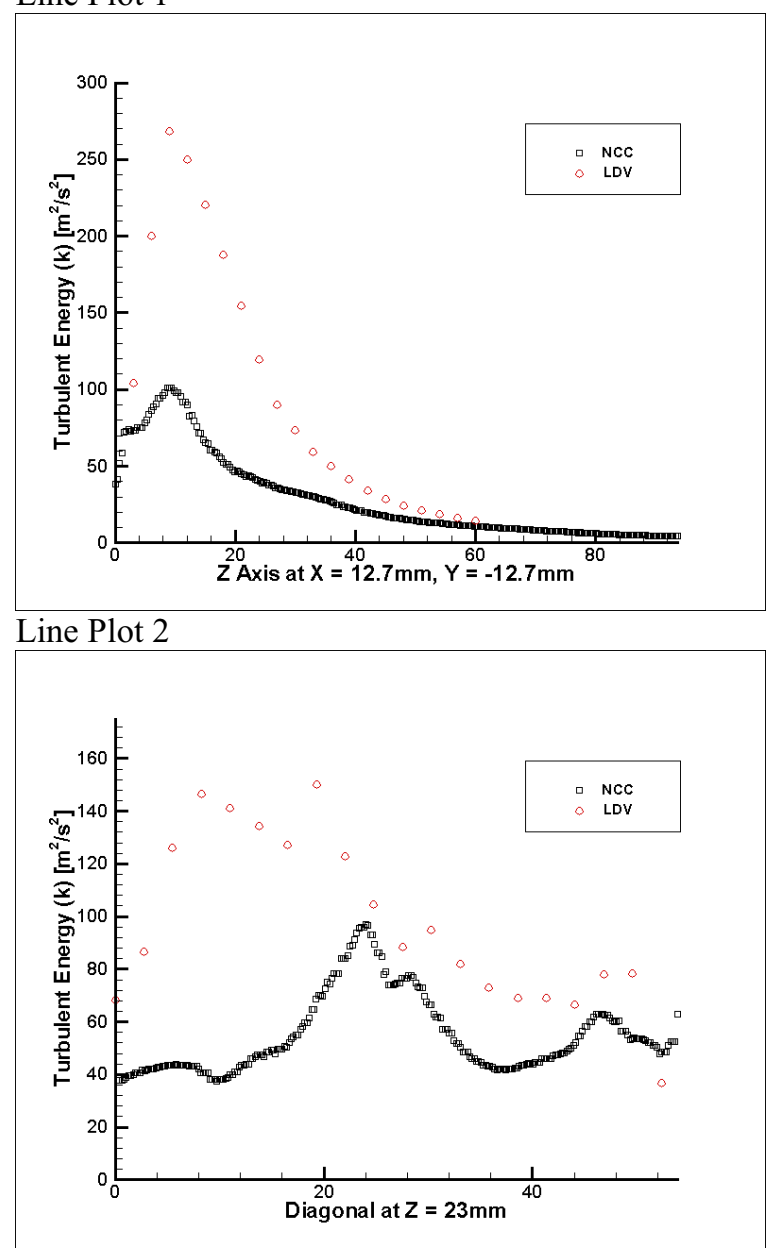

Line Plot 3

Figure 32 - Comparisons between NCC Computations and LDV Measurements, Turbulent Kinetic Energy (k) at Line Plots 1,2, and 3
Figure 32 shows a comparison for the turbulent kinetic energy $(\mathrm{k})$ for Line Plots $1-3$. At Line Plot 1 , the agreement is good, with the value of $\mathrm{k}$ within $20 \%$ of the experimental data. Line Plot 2 shows a general trend, but the value is off by more than $50 \%$ in the $5-$ $25 \mathrm{~mm}$ region. For Line Plot 3, a general trend is shown, with data off by more than $50 \%$ in the $0-$ $20 \mathrm{~mm}$ region. Past $20 \mathrm{~mm}$, the NCC agrees with the LDV data to within $20-30 \%$ (approaching the corner).

\section{DISCUSSION}

The NCC computations tend to compare well with the LDV measurements in some regions and compare poorly in other regions of the LDI swirler. The NCC computations generally show the same trends as the experimental data. However, the LDV data cannot be considered the absolute reference at this time. Because of the symmetry method, the $\mathrm{U}$ and $\mathrm{V}$ velocities are essentially the same (they are opposite). The $\mathrm{U}$ velocity is the measured velocity component. The NCC computations diverge for the V velocity downstream of the injector. This trend is not consistent with any other variable. Because of this, the $\mathrm{V}$ velocity should be measured. The W Velocity compares well for most of the one, two, and three-dimensional representations. While the turbulent kinetic energy is not the same for all of the contour plots, the line plots indicate a trend. The turbulent kinetic energy is also affected by the $U_{\text {rms }}$ measurement. (See Equation (1) for the definition of k.) The NCC can predict the general trends for the vast majority of the flow field, and compares well in specific regions. Because of this, the NCC can be used as a design tool. Nevertheless, improvements should be made to the NCC.

The line plots indicate that the NCC poorly predicts flow quantities in regions of strong gradients. To improve this, two steps should be taken. The first step is to scale the numerical dissipation with matrix dissipation instead of scalar numerical dissipation. The methods suggested by Swanson and Turkel for non reacting flows ${ }^{15}$, and Gerlinger et al for reacting flows should be used. $^{16}$ Results indicate that matrix dissipation greatly improves the accuracy of central difference finite volume CFD codes. The second step is to add Adaptive Mesh Refinement (AMR) to the NCC. This is needed because it is nearly impossible to correctly setup a computational mesh for very complex flows. The Pyramid 3D package is an excellent candidate to do the AMR in NCC. ${ }^{17}$

Turbulence modeling also needs to be improved. A "unified" turbulence model should be implemented in the NCC. ${ }^{18}$ This model would combine a wall distance free, cubic non-linear, k-epsilon, low Reynolds turbulence model with the current dynamic wall function. This would give the benefits of a low 
Reynolds number model in regions of high gradients without the sensitivity of grid point placement. In addition, the Reynolds stresses should be stored during NCC computations.

\section{CONCLUSIONS}

A Comparison between NCC computations and LDV measurements was made. This comparison showed that the NCC was able to predict the general trends of the flow field. Because of this study, the NCC can be used as a design tool for LDI injectors. Suggestions were given on how to further improve the NCC for turbulent, three-dimensional, recirculating flows.

\section{REFERENCES}

1. Stubbs, R., M., and Liu, N.-S., (1997), "Preview of the National Combustion Code", AIAA 97-3114, $33^{\text {rd }}$ AIAA/ASME/SAE/ASEE Joint Propulsion Conference and Exhibit, July 6-9, Seattle, WA, USA.

2. Quealy, A., Ryder, R., Norris, A., and Liu, N.-S., (2000), "National Combustion Code: Parallel Implementation and Performance", NASA TM-2000209801.

3. Shih, T.-H., Povinelli, L. A., Liu, N.-S and Chen, K.-H., (2000), "Generalized Wall Function for Complex Turbulent Flows", NASA TM-2000-209936.

4. Chien, K. Y., (1982), "Prediction of Boundary Layer Flows with a Low - Reynolds Number Turbulence Model", AIAA J., Vol. 20, No. 1, pp 33-38.

5. Shih, T.-H., Chen, K.-H., Liu, N.-S., Lumley, J. L., (1998), "Modeling of Turbulent Swirling Flows", NASA-TM -113112 .

6. Shih, T.-H., Chen, K.-H., and Liu, N.-S., (1998), "A Non-Linear k-epsilon Model for Turbulent Shear Flows", AIAA Paper 98-3983.

7. Chen, K.-H., Norris, A. T., Quealy, A., and Liu, N.S., (1998), "Benchmark Test Cases for The National Combustion Code.", 34 ${ }^{\text {th }}$ AIAA/ASME/SAE/ASEE Joint Propulsion Conference and Exhibit, July 13-15, Cleveland, OH, USA.

8. Iannetti, A. C., Chen, K.-H., (2000), “An Initial Comparison of National Combustor Code Simulations Using Various Chemistry Modules with Experimental Gas Turbine Combustor Data", AIAA - 2000 - 0330, $38^{\text {th }}$ AIAA Aerospace Sciences Meeting, Reno, NV, USA.

9. CFD-GEOM, Interactive 3D Geometry Modeling and Mesh Generation (Structured, Unstructured, and Mixed-Element Meshes), CFD Research Corporation, 215 Wynn Drive, Huntsville, AL 35805, USA, http://www.cfdrc.com/.
10. Swanson, R. C., and Turkel, E., (1997), "Multistage Schemes with Multigrid for Euler and Navier - Stokes Equations", NASA-TP-3631.

11. Jeng, S.-M., Cai, J., Tacina, R., (2001), "MultiSwirler Aerodynamics: Experimental Measurements", To be presented at the 37th AIAA/ASME/SAE/ASEE Joint Propulsion Conference and Exhibit, July 8-11, Salt Palace, Salt Lake City, UT, USA.

12. TSI Incorporated, Laser Diagnostic Instruments, PO Box 64204, St. Paul, Minnesota 55164, USA, http://www.tsi.com/fluid/homepage/fmidhome.htm.

13. Ensight Gold, A High End Post Processing Tool, CEI, Inc., 600 Airport Blvd., Suite 500, Morrisville, NC 27560, USA, http://www.ceintl.com/.

14. Tecplot, A General Plotting and Post Processing Tool, Amtec Engineering, Inc., PO Box 3633, Bellevue, WA 98009-3633, USA, http://www.amtec.com/.

15. Swanson, R. C., and Turkel, E., (1993), "Aspects of a High-Resolution Scheme for the Navier-Stokes Equations", AIAA Paper 93-3372-CP.

16. Gerlinger, P., Algermissen, J., Bruggemann, D., (1995), "Matrix Dissipation for Central Difference Schemes with Combustion"AIAA J., Vol. 33, No. 10, pp 1865-70.

17. Lou, J., Norton, C. D., and Cwik, T., "Pyramid: A Two and Three-Dimensional Software Package for Parallel Adaptive Mesh Refinement in Unstructured Computations", (1999), In Proc. 1999 Intl. Conf. on Advanced Simulation Technologies, San Diego, CA, April 11-15, 1999, Also as NASA Tech Brief, October, 1999.

18. (2000), Private Communication between T.-H. Shih and the NCC group. 
Public reporting burden for this collection of information is estimated to average 1 hour per response, including the time for reviewing instructions, searching existing data sources, gathering and maintaining the data needed, and completing and reviewing the collection of information. Send comments regarding this burden estimate or any other aspect of this collection of information, including suggestions for reducing this burden, to Washington Headquarters Services, Directorate for Information Operations and Reports, 1215 Jefferson Davis Highway, Suite 1204, Arlington, VA 22202-4302, and to the Office of Management and Budget, Paperwork Reduction Project (0704-0188), Washington, DC 20503.

\begin{tabular}{|l|l|l}
\hline 1. AGENCY USE ONLY (Leave blank) & $\begin{array}{c}\text { 2. REPORT DATE } \\
\text { March } 2001\end{array}$ & $\begin{array}{r}\text { 3. REPORT TYPE AND DATES COVERED } \\
\text { Technical Memorandum }\end{array}$ \\
\hline
\end{tabular}

\section{TITLE AND SUBTITLE} 5. FUNDING NUMBERS

Towards Accurate Prediction of Turbulent, Three-Dimensional, Recirculating Flows With the NCC

6. AUTHOR(S)

WU-714-02-50-00

A. Iannetti, R. Tacina, S.-M. Jeng, and J. Cai

7. PERFORMING ORGANIZATION NAME(S) AND ADDRESS(ES)

National Aeronautics and Space Administration

John H. Glenn Research Center at Lewis Field

Cleveland, Ohio 44135-3191

8. PERFORMING ORGANIZATION REPORT NUMBER

E-12724

\section{SPONSORING/MONITORING AGENCY NAME(S) AND ADDRESS(ES)}

National Aeronautics and Space Administration

Washington, DC 20546-0001

10. SPONSORING/MONITORING AGENCY REPORT NUMBER

NASA TM-2001-210761

AIAA-2001-0809

\section{SUPPLEMENTARY NOTES}

Prepared for the 39th Aerospace Sciences Meeting and Exhibit sponsored by the American Institute of Aeronautics and Astronautics, Reno, Nevada, January 8-11, 2001. A. Iannetti and R. Tacina, NASA Glenn Research Center; S.-M. Jeng and J. Cai, University of Cincinnati, Cincinnati, Ohio 45221-0001. Responsible person, A. Iannetti, organization code 5830, 216-433-5586.

12a. DISTRIBUTION/AVAILABILITY STATEMENT 12b. DISTRIBUTION CODE

Unclassified - Unlimited

Subject Categories: 02, 07, and 34

Distribution: Nonstandard

Available electronically at http://gltrs.grc.nasa.gov/GLTRS

This publication is available from the NASA Center for AeroSpace Information, 301-621-0390.

\section{ABSTRACT (Maximum 200 words)}

The National Combustion Code (NCC) was used to calculate the steady state, nonreacting flow field of a prototype Lean Direct Injection (LDI) swirler. This configuration used nine groups of eight holes drilled at a thirty-five degree angle to induce swirl. These nine groups created swirl in the same direction, or a corotating pattern. The static pressure drop across the holes was fixed at approximately four percent. Computations were performed on one quarter of the geometry, because the geometry is considered rotationally periodic every ninety degrees. The final computational grid used was approximately 2.26 million tetrahedral cells, and a cubic nonlinear $\mathrm{k}-\varepsilon$ model was used to model turbulence. The NCC results were then compared to time averaged Laser Doppler Velocimetry (LDV) data. The LDV measurements were performed on the full geometry, but four ninths of the geometry was measured. One-, two-, and three-dimensional representations of both flow fields are presented. The NCC computations compare both qualitatively and quantitatively well to the LDV data, but differences exist downstream. The comparison is encouraging, and shows that NCC can be used for future injector design studies. To improve the flow prediction accuracy of turbulent, three-dimensional, recirculating flow fields with the NCC, recommendations are given.

\section{SUBJECT TERMS} 15. NUMBER OF PAGES

Computational fluid dynamics; Validation; Combustor swirler; Turbulence measurements; Lean direct injection

17. SECURITY CLASSIFICATION OF REPORT

Unclassified

18. SECURITY CLASSIFICATION
OF THIS PAGE
Unclassified

Unclassified

\section{SECURITY CLASSIFICATION OF ABSTRACT}

Unclassified 